\title{
Src-Class Kinases Act within the Agrin/MuSK Pathway to Regulate Acetylcholine Receptor Phosphorylation, Cytoskeletal Anchoring, and Clustering
}

\author{
Ali S. Mohamed, Kimberly A. Rivas-Plata, Jonathan R. Kraas, Suha M. Saleh, and Sheridan L. Swope \\ Department of Neuroscience, Georgetown University Medical Center, Washington DC 20007-2197
}

Synaptogenesis at the neuromuscular junction requires agrininduced stable localization of acetylcholine receptors (AChRs) at the endplate. The effects of agrin are transduced by the muscle-specific receptor tyrosine kinase (MuSK). This study provides evidence that Src-class protein tyrosine kinases mediate the effects of agrin-activated MuSK to regulate clustering and anchoring of AChRs in skeletal muscle. MuSK was complexed with both Src and Fyn in the C2 mouse muscle cell line. These associations were enhanced by agrin and by increasing protein tyrosine phosphorylation with pervanadate. Coupling between MuSK and the Src-class kinases in vivo appeared to be caused by a phosphotyrosine-SH2 domain interaction because binding of MuSK to the SH2 domains of Fyn and Src in vitro was specific, enhanced by phosphorylation, and dependent on MuSK autophosphorylation. In addition, Src and Fyn phosphorylated MuSK. AChR phosphorylation, stimulated by agrin or pervanadate, was inhibited by blocking Src-class kinases with PP1. Furthermore, agrin-induced clustering and cytoskeletal anchoring of AChRs was dependent on Src-family kinases. These data support the conclusion that Fyn and Src act downstream of MuSK to regulate the stable localization of AChRs at the neuromuscular endplate during agrin-induced synaptogenesis.

Key words: synaptogenesis; neuromuscular junction; Src; Fyn; skeletal muscle; cytoskeleton; phosphorylation; MuSK; agrin; PP1; Src homology 2 domain; pervanadate
Synaptogenesis is best understood at the neuromuscular junction (NMJ), where many of the molecular players have been identified (Hall and Sanes, 1993; Sanes and Lichtman, 1999). In the immature myotube, nicotinic acetylcholine receptors (AChRs) are dispersed throughout the membrane. During innervation, the receptors become stably localized to the site of nerve-muscle contact. One of the major goals in studying the NMJ is to determine the mechanism by which AChRs are concentrated underneath the motor nerve terminal. During synaptogenesis, mobile AChRs are likely to diff use to the neuron contact site and become anchored there. This process, known as "diff usion trap," is a model originally proposed by Edwards and Frisch (1976).

Three proteins critical to the formation of the NMJ endplate are agrin, the muscle-specific receptor tyrosine kinase (MuSK), and rapsyn. Agrin is a neuron-derived factor that induces postsynaptic differentiation events, including clustering, cytoskel-

Received Jan. 23, 2001; revised March 15, 2001; accepted March 19, 2001.

This work was supported by National Institutes of Health Grant NS35505 and the Muscular Dystrophy Association. We thank Dr. R. L. Huganir for rapsyn pGW1CMV, myc-tagged Torpedo MuSK and inactive MuSK constructs, anti-rat agrin antibody (JH1037), anti-myc rabbit polyclonal (JH2235), and the phosphorylationspecific anti-AChR $\beta$ (JH1360) and anti- $\delta$ (JH1358) subunit antibodies. We thank Dr. Z. W. Hall for the anti-MuSK rabbit polyclonal antibody, Dr. E. Ralston for the C2 cell line, Dr. S. Parsons for the Src-pCDNA3 construct, Dr. S. Desiderio for the Bruton's tyrosine kinase in pCIS-2, Dr. M. Ferns for the agrin constructs agrin C-4,8 and agrin $\mathrm{C}-0,0$, Dr. C. R. King for the pGEX Grb2 SH2 construct, and Dr. J. Lindstrom for the rat monoclonal antibody (mAb 148) against the AChR $\beta$ subunit. We also thank Anne Miermont for affinity purification of anti-Src-PY ${ }^{416}$ antibody, GW001. We thank Arlene Santos, Fa Yang, and Kate Landau for excellent technical assistance, and Dr. William Rosoff for helpful discussions.

Correspondence should be addressed to Dr. Sheridan L. Swope, EP08 Research Building, Department of Neuroscience, Georgetown University Medical Center, 3970 Reservoir Road NW, Washington DC 20007. E-mail: swopes@giccs. georgetown.edu.

Dr. Mohamed's present address: Neurologic Inc., 15010 Broschart Road, Suite 200, Rockville, MD 20850.

Copyright () 2001 Society for Neuroscience $0270-6474 / 01 / 213806-13 \$ 15.00 / 0$ etal anchoring, and phosphorylation of AChRs (Godfrey et al., 1984; Wallace et al., 1991; Wallace, 1995; Gautam et al., 1996; Cohen et al., 1997; Jones et al., 1997; Meier et al., 1997; Rimer et al., 1997). Previous studies indicate that the receptor for agrin includes MuSK (DeChiara et al., 1996; Glass et al., 1996). For example, MuSK-deficient myotubes fail to cluster AChRs in response to agrin (Glass et al., 1996). Rapsyn is a cytoskeletal, peripheral membrane protein crucial for AChR clustering and anchoring at the postsynaptic endplate (Barrantes et al., 1980; Burden et al., 1983; Walker et al., 1984; Froehner et al., 1990; Phillips et al., 1993; Gautam et al., 1995). In rapsyn minus myotubes, agrin activates MuSK but does not induce phosphorylation or clustering of AChRs, indicating that rapsyn transduces the action of agrin-activated MuSK (Gautam et al., 1995; Apel et al., 1997). Although insights into the mechanism for synaptogenesis at the NMJ have been gained, the exact relationships among agrin, MuSK, and rapsyn remain to be determined.

Protein tyrosine phosphorylation is important for AChR clustering and cytoskeletal anchoring (Meier et al., 1995; Wallace, 1995; Ferns et al., 1996; Fuhrer et al., 1997; Swope et al., 1999). It has been suggested that a kinase downstream of MuSK directly phosphorylates AChRs (Apel et al., 1997; Fuhrer et al., 1997). Src-class kinases represent the predominant protein tyrosine kinase activity in AChR-enriched postsynaptic membranes (Swope and Huganir, 1993). Src-family kinases complex with the AChR and phosphorylate the receptor in vitro (Swope and Huganir, 1993, 1994; Fuhrer and Hall, 1996). The functional significance of AChR phosphorylation by Src-class kinases may be in anchoring the receptor to the cytoskeleton. For example, Src-family kinases are complexed with rapsyn, and activation of Src-class kinases by rapsyn in heterologous cells results in AChR phosphorylation and cytoskeletal binding (Mohamed and Swope, 1999). The goal of the present study was to further clarify the signal transduction 
cascade by which Src-family kinases may mediate synaptogenesis at the NMJ. The relationship between MuSK and Src-class kinases was explored. In addition, we examined whether the effects of agrin to stimulate AChR phosphorylation, cytoskeletal anchoring, and clustering are dependent on Src-class kinases.

\section{MATERIALS AND METHODS}

Constructs. The full-length coding sequence of Torpedo Fyn in pBKCMVAlac (pBK-CMV) was described previously (Mohamed and Swope, 1999). Src and the dominant negative Src in pCDNA3 (Biscardi et al., 1999) were gifts from Dr. S. Parsons (University of Virginia, Charlottesville, VA). Mouse rapsyn in pGW1-CMV, myc-tagged Torpedo MuSK, catalytically inactive myc-tagged MuSK (MuSK[K686R]), and empty vector pBK-CMV (Gillespie et al., 1996) were generous gifts from Dr. R. L. Huganir (Johns Hopkins University). The Bruton's tyrosine kinase (Btk) cDNA in pCIS-2 (Yang et al., 1995) was a gift from Dr. S. Desiderio (Johns Hopkins University). The construct encoding neural-specific agrin (C-agrin 4,8) (Ferns et al., 1993) was a gift from Dr. M. Ferns (McGill University, Montreal, Canada). pGEX2T Fyn and Src $\mathrm{SH} 2$ domain fusion proteins were prepared as described previously (Swope and Huganir, 1993). Src SH2 domain fusion protein construct was prepared by PCR using a proviral pRSV-vSrc (DeLorbe et al., 1980) as a template followed by subcloning into pGEX-2T as described (Swope and Huganir, 1994). The proviral pRSV-vSrc was a gift from Dr. J. Brugge, originally from Dr. J. M. Bishop (University of California, San Francisco). pGEX Grb2 SH2 construct (Oligino et al., 1997) was a gift from Dr. C. R. King (Georgetown University, Washington, DC).

Antibodies. The anti-myc rabbit polyclonal (JH2235) raised against the peptide EQKLISQQDL and anti-rat agrin rabbit polyclonal (JH1037) raised against the peptide sequence (K)LEDAVTKPELRPCPT corresponding to amino acids $1922-1936$ in the C terminus of rat agrin were gifts from Dr. R. Huganir (Johns Hopkins University). The rat monoclonal antibody (mAb) 148 against the AChR $\beta$ (Ratnam et al., 1986) was a gift from Dr. J. Lindstrom (University of Pennsylvania, Philadelphia, PA). The C-terminal rabbit anti-Src antibody that recognizes all Src kinases ( $\operatorname{src} 2)$, the N-terminal Fyn-specific antibody (FYN 3), the Nterminal Fyn-specific mouse monoclonal (FYN 15), the N-terminal MuSKspecific goat polyclonal antibody (N19), the C-terminal MuSK-specific goat polyclonal antibody (C19), and the monoclonal anti-phosphotyrosine antibody (PY99) were purchased from Santa Cruz Biotechnology (Santa Cruz, CA). The affinity-purified anti-MuSK rabbit polyclonal antibody, $\alpha$-MuSKZH (Fuhrer et al., 1997), was a gift from Dr. Z. W. Hall [National Institute of Neurological Disorders and Stroke (NINDS), National Institutes of Health (NIH), Bethesda, MD]. The anti-myc 9E10 ascites were purchased from Sigma (St. Louis, MO). The monoclonal anti-phosphotyrosine antibody, 4G10, and the Src-specific monoclonal antibody, GD11, were purchased from Upstate Biotechnology (Lake Placid, NY). The Src-specific mouse monoclonal antibody, Ab-1, was purchased from OncogeneCalbiochem (Cambridge, MA). The phosphorylation-state-specific antiSrc-family kinase antibody, GW001, was raised against the phosphopeptide KRLIEDNEpY ${ }^{416}$ TARQG corresponding to the amino acids 409421 in the catalytic domain of avian c-Src, to which an amino terminal lysine was added. The antiserum was affinity purified by applying the flow-through of a column containing nonphosphorylated peptide to an affinity column derived from the phosphopeptide. The purified anti-Srcclass kinase phosphorylation state-specific antibodies were then eluted from the KRLIEDNEpY ${ }^{416}$ TARQG column. A MuSK-specific rabbit antiserum, GW002, was made against the peptide KPSFCSIHRILQRMCERAEGTVGV corresponding to the C-terminal 23 amino acids of mouse MuSK with an amino terminal lysine.

Cell culture and transfection. Cell culture reagents were purchased from Life Technologies (Gaithersburg, MD). The mouse muscle cell line C2C12 (C2), obtained from Dr. E. Ralston (NINDS, NIH), was grown and maintained in growth media composed of DMEM, 20\% FBS, and $0.5 \%$ chick embryo extract. For induction of differentiation, myoblasts at $60-80 \%$ confluence were switched to a low serum differentiation media (DM) composed of DMEM plus 2\% horse serum. For experiments examining the effect of pervanadate and/or PP1 treatments on phosphorylation, cytoskeletal anchoring, or clustering, cells were grown on collagen- or gelatin-coated dishes. The quail fibroblast cell line, QT-6 (Moscovici et al., 1977), was maintained as described (Blount and Merlie, 1988). COS-7 cells were grown and maintained as described (Gluzman, 1981). QT-6 or COS-7 cell cultures at $\sim 50 \%$ confluence were transfected using the calcium phosphate method of Chen and Okayama (1987). For
QT-6 transfection, $2 \mu \mathrm{g}$ each of inactive MuSK[K686R], MuSK, rapsyn, Fyn, Src, Btk, or pBK-CMV plasmid constructs was used per $60 \mathrm{~mm}$ dish, and $\mathrm{pBK}-\mathrm{CMV}$ was added, if necessary, to bring the total amount of plasmid DNA to $12 \mu \mathrm{g}$ per dish. For transfection of COS-7 cells, $30 \mu \mathrm{g}$ of agrin 4,8 was used per $100 \mathrm{~mm}$ dish. In each case, transfection efficiency was typically $\geq 50 \%$, as determined by the Green Lantern vector (Life Technologies). For transfection of C2 cells, $2 \mu \mathrm{g}$ dominant negative Src or empty plasmid was mixed with $3 \mu$ l of FuGene (Roche) and $100 \mu \mathrm{l}$ of serum-free DMEM and pipetted directly onto $35 \mathrm{~mm}$ wells containing $60-80 \%$ confluent myoblasts. After 1-2 min, $2 \mathrm{ml}$ of DM was added, and the cells were returned to the incubator. After $48 \mathrm{hr}$, the medium was replaced with fresh DM, and the cells were treated with or without agrin $10 \mathrm{hr}$ later. Transfection efficiency was typically $\sim 20 \%$, as determined by the Green Lantern vector.

Phosphorylation of MuSK in QT-6 cells. Transfected QT-6 cells expressing MuSK or MuSK[K686R] were solubilized in 2\% SDS, $50 \mathrm{~mm}$ Tris, $\mathrm{pH}$ 7.4, $150 \mathrm{~mm} \mathrm{NaCl}, 2 \mathrm{~mm}$ EDTA, 4 mM EGTA, 2 mm sodium orthovanadate (SDS-lysis buffer) for $10 \mathrm{~min}$ at $22^{\circ} \mathrm{C}$. The lysates were diluted to a final concentration of $0.4 \%$ SDS and $2 \%$ Triton X-100 at $1 \mathrm{mg} / \mathrm{ml}$ protein. Lysates were sonicated for $30 \mathrm{sec}$ on ice and spun at $225,000 \times$ $g$ for $10 \mathrm{~min}$ at $4^{\circ} \mathrm{C}$. Solubilized proteins after centrifugation were immunoprecipitated with the polyclonal anti-myc antibody (JH2235). Immunoprecipitates were analyzed by Western blotting using a mixture of anti-phosphotyrosine monoclonal antibodies 4G10 and PY99.

Phosphorylation of MuSK and AChR in C2 myotubes. C2 myotubes were preincubated for $1 \mathrm{hr}$ in DMEM supplemented with $0.1 \%$ horse serum followed by pretreatment with or without 10 or $20 \mu \mathrm{M}$ PP1 for $1 \mathrm{hr}$. Myotubes were then incubated with or without $100 \mathrm{pM}$ agrin or $30 \mu \mathrm{M}$ pervanadate. Treated myotubes were rinsed twice with ice-cold PBS and solubilized on ice for $10 \mathrm{~min}$ using $50 \mathrm{~mm}$ Tris, $\mathrm{pH} 7.4,1 \%$ Triton X-100, $1 \%$ sodium deoxycholate, $0.1 \%$ SDS, $150 \mathrm{~mm} \mathrm{NaCl}, 2$ mm EDTA, $4 \mathrm{~mm}$ EGTA, and $1 \mathrm{~mm}$ sodium vanadate (RIPA buffer) supplemented with the protease inhibitors, $0.1 \mathrm{~mm}$ phenylmethylsulfonylfluoride, $10 \mu \mathrm{g} / \mathrm{ml}$ pepstatin, $10 \mu \mathrm{g} / \mathrm{ml}$ chymostatin, $10 \mathrm{mg} / \mu \mathrm{l}$ antipain, and $10 \mathrm{U} / \mu \mathrm{l}$ Trasylol. Lysates were centrifuged at $225,000 \times g$ for $10 \mathrm{~min}$, and the supernatants were immunoprecipitated with antibodies specific for MuSK (GW002) or AChR (88b). Phosphorylation of MuSK was analyzed by Western blotting with a mixture of the anti-phosphotyrosine antibodies, 4G10 and PY99. Phosphorylation of AChR was detected with a mixture of the phosphorylation state-specific anti-AChR $\beta$ subunit, JH1360, and antiAChR $\delta$ subunit, JH1358. AChR blots were stripped and reprobed with AChR $\beta$ subunit mAb 148.

Binding of MuSK to SH2 fusion proteins. SH2 domain fusion proteins were prepared as described previously (Swope and Huganir, 1994). In brief, the cDNAs for SH2 domains from Src-class kinases and Grb2 were inserted into a bacterial expression vector containing the sequence for glutathione $S$-transferase (GST). The SH2-GST fusion protein was grown in BL21 bacteria and purified on glutathione agarose (Sigma). The fusion protein still bound to the agarose was subsequently used as an affinity reagent. Transfected QT-6 cells expressing MuSK or MuSK[K686R] were solubilized in SDS-lysis buffer for $10 \mathrm{~min}$ at $22^{\circ} \mathrm{C}$. The lysates were diluted to a final concentration of $0.4 \%$ SDS plus $2 \%$ Triton X-100, sonicated for $30 \mathrm{sec}$ on ice, and spun at $225,000 \times g$ for 10 $\min$ at $4^{\circ} \mathrm{C}$. Solubilized proteins, after centrifugation, were incubated with the $\mathrm{SH} 2$ domain fusion protein affinity resin for $2 \mathrm{hr}$, and nonspecific proteins were washed away as described previously (Swope and Huganir, 1994). Binding of MuSK was detected by Western analysis using anti-myc mouse monoclonal 9E10.

Immunoprecipitation and coimmunoprecipitation. $\mathrm{C} 2$ myotubes were rinsed with ice-cold PBS and solubilized for $15 \mathrm{~min}$ either in $50 \mathrm{~mm}$ Tris, pH 7.4, $150 \mathrm{~mm} \mathrm{NaCl}, 4$ mm EGTA, 4 mm EDTA, $1 \%$ Triton X-100, and $2 \mathrm{~mm}$ Na-orthovanadate (Triton lysis buffer) or in RIPA buffer supplemented with the protease inhibitors, $0.1 \mathrm{~mm}$ phenylmethylsulfonylfluoride, $10 \mu \mathrm{g} / \mathrm{ml}$ pepstatin, $10 \mu \mathrm{g} / \mathrm{ml}$ chymostatin, $10 \mathrm{mg} / \mu \mathrm{l}$ antipain, and $10 \mathrm{U} / \mu \mathrm{l}$ Trasylol. Lysates were centrif uged at $225,000 \times g$ for $10 \mathrm{~min}$, and the supernatants were immunoprecipitated with antibodies specific for MuSK (a mixture of N19 and C19 or, alternatively, GW002), AChR (88b), Fyn (Fyn 15), or Src (Ab-1). Immunoprecipitates were analyzed for precipitated or coprecipitated proteins by immunoblotting using specific antibodies for MuSK ( $\alpha$-MuSK-ZH), a mixture of the phosphorylation state-specific anti-AChR $\beta$ subunit (JH1360), and anti-AChR $\delta$ subunit (JH1358) antibodies, AChR $\beta$ subunit (mAb 148), Fyn (Fyn 3), Src (GD11), or Fyn and/or Src (Src2).

Detergent extraction. C2 myotubes were preincubated with DME-F12 (Sigma) supplemented with $1 \mathrm{mg} / \mathrm{ml}$ bovine serum albumin (BSA) (RIA 
Grade, Sigma) and pretreated with or without 10-20 $\mu \mathrm{M}$ PP1 followed by treatment with or without $100 \mathrm{pM}$ agrin. Treated myotubes were rinsed twice with ice-cold PBS and extracted on ice with 10 mM HEPES, pH 7.4, $50 \mathrm{~mm} \mathrm{NaCl}, 300 \mathrm{~mm}$ sucrose, $1 \mathrm{~mm} \mathrm{MgCl}_{2}$, and $1 \mathrm{~mm} \mathrm{Na}$-orthovanadate (Prives buffer) (Prives et al., 1982) containing 0.5\% Triton X-100 and the protease inhibitors $0.1 \mathrm{~mm}$ phenylmethylsulfonylfluoride, $10 \mu \mathrm{g} / \mathrm{ml}$ pepstatin, $10 \mu \mathrm{g} / \mathrm{ml}$ chymostatin, $10 \mathrm{mg} / \mu \mathrm{l}$ antipain, and $10 \mathrm{U} / \mu \mathrm{l}$ Trasylol. Treatment of cultured myotubes with Prives buffer rapidly extracts the plasma membrane and other membranous organelles but leaves the cytoskeleton intact (Prives et al., 1982). After the desired time, the buffer was removed, and the cells were rinsed once with Prives buffer with $0.1 \%$ Triton X-100. Residual cytoskeletal proteins were solubilized and scraped from the dish with SDS-PAGE sample buffer, sonicated for 30 sec, and spun at $225,000 \times g$ for $10 \mathrm{~min}$ at $4^{\circ} \mathrm{C}$. Solubilized cytoskeletal proteins were analyzed by SDS-PAGE and Western blotting using rat $\mathrm{mAb} 148$, specific for the AChR $\beta$ subunit. For determining the effects of PP1 on the amount of AChRs, sister $\mathrm{C} 2$ cultures were treated and processed as above, except the Prives buffer contained no Triton X-100.

In vitro kinase assays. $\mathrm{C} 2$ myotubes were washed two times in ice-cold PBS and then solubilized in RIPA buffer plus the protease inhibitors 0.1 $\mathrm{mM}$ phenylmethylsulfonylfluoride, leupeptin $10 \mu \mathrm{g} / \mathrm{ml}$, and $10 \mathrm{U} / \mu \mathrm{l}$ Trasylol. Lysates were spun at $225,000 \times g$ for $10 \mathrm{~min}$ at $4^{\circ} \mathrm{C}$. Supernatants from each $60 \mathrm{~mm}$ dish of $\mathrm{C} 2$ myotubes were divided into three equal portions. One-third of each supernatant was used for immunoprecipitation of Fyn, using mAb Fyn 15, Src using mAb Ab-1, or MuSK using GW002. The immunocomplexes were immobilized using protein G- or protein A-Sepharose and washed three times in RIPA buffer, then twice in kinase reaction buffer without ATP. The immunoprecipitates were used in an in vitro phosphorylation reaction with $20 \mu \mathrm{M}$ ATP and $7.5 \mu \mathrm{g}$ acid-denatured enolase as described previously (Feder and Bishop, 1990). The reactions were analyzed by Western blotting with a mixture of the anti-phosphotyrosine antibodies, 4G10 and PY99.

Treatments with $P P 1$, agrin, or pervanadate. For biochemical analysis, C2 myotubes were preincubated in DMEM supplemented with $0.1 \%$ horse serum for $1 \mathrm{hr}$, then PP1, agrin, or pervanadate were added directly to the medium. For detergent extraction experiments, $\mathrm{C} 2$ myotubes were preincubated for $1 \mathrm{hr}$ in DME-F12 medium supplemented with $0.1 \%$ RIA grade BSA before agrin or PP1 treatments. Q-T6 cells were treated with pervanadate in growth medium containing Medium 199 (Life Technologies) supplemented with $1 \%$ DMSO, $5 \%$ FBS, $10 \%$ tryptose phosphate broth, and $1 \%$ penicillin-streptomycin. For microscopic analysis of clustering, myotubes in DM were treated overnight with agrin. The concentrations of agrin, pervanadate, and PP1 were $100 \mathrm{pM}, 30 \mu \mathrm{M}$, and $10-20 \mu \mathrm{M}$, respectively.

Immunocytochemistry. Myotubes in DM were incubated at $37^{\circ} \mathrm{C} / 8 \%$ $\mathrm{CO}_{2}$ for $1 \mathrm{hr}$ with $80 \mathrm{~nm}$ tetramethyl(rhodamine)- $\alpha$-bungarotoxin or Texas Red- $\alpha$-bungarotoxin (Molecular Probes, Eugene, OR). Cells at room temperature were washed with PBS, fixed for 15 min with $3 \%$ paraformaldehyde $/ 4 \%$ sucrose, and then permeabilized with $0.1 \%$ Triton $\mathrm{X}-100$ for $5 \mathrm{~min}$. Myotubes expressing the dominant negative Src were identified by double labeling with the pan-Src kinase antibody, $s r c 2$, followed by FITC-goat-anti-rabbit secondary antibody (Molecular Probes). Cells were visualized by epifluorescence on a Nikon Eclipse TE300 inverted microscope using a $20 \times$ objective. Images were captured with a Magnafire digital camera and software. Cluster sizes were analyzed with Adobe Photoshop.

Immunoblotting. Proteins were resolved by SDS-PAGE and transferred to polyvinylidene difluoride (PVDF) membranes (Immobilon, Millipore, Bedford, MA) by electroblotting. The PVDF membranes were blocked in 5\% nonfat milk in Tris-buffered saline (50 mM Tris, $\mathrm{pH} 7.4,200 \mathrm{~mm}$ $\mathrm{NaCl}$ ) containing $0.05 \%$ Tween 20 . For phosphotyrosine immunoblotting, the PVDF membranes were blocked in 3-5\% BSA. The dilutions for primary antibodies were as follows: anti-MuSK antibody ( $\alpha$-MuSK$\mathrm{ZH}$ ), anti-phosphotyrosine 4G10, anti-phosphotyrosine PY99, and antiAChR $\beta$ subunit mAb 148, each at 1:1000; anti-Fyn (Fyn3) and Src2 (Pan-Src), each at 1:500; anti-myc mouse monoclonal (9E10), anti-active state Src kinase-specific rabbit antibody (GW001), and anti-Src mouse monoclonal (GD11), each at 1:200. Horseradish peroxidase-conjugated secondary antibodies were from Jackson ImmunoResearch Laboratories (West Grove, PA) and were used at dilutions of 1:50,000. Horseradish peroxidase-bound signal was detected using an enhanced chemiluminescence (ECL) (Pierce, Rockford, IL) followed by exposure of BioMax MR-1 film (Eastman Kodak, Rochester, NY) or, for greater sensitivity, HyperFilm ECL (Amersham, Arlington Heights, IL). For some experiments, blots were stripped by incubation at $55^{\circ} \mathrm{C}$ for $30 \mathrm{~min}$ in $62.5 \mathrm{~mm}$
Tris, pH 6.8, 2\% SDS, and $100 \mathrm{~mm} \beta$-mercaptoethanol and reanalyzed by Western blotting.

Agrin production. Medium from COS-7 cells expressing a C-agrin 4,8 or transfected with empty plasmid pBK-CMV was collected and replaced each day for $2 \mathrm{~d}$. The concentration of agrin in the collected medium was determined by Western blotting (Sugiyama et al., 1994) using agrinspecific polyclonal antiserum (JH1037) and standard purified agrin of known concentration provided by Dr. J. E. Sugiyama (NINDS, NIH).

Fusion protein production. SH2 domain fusion proteins derived from Fyn, Src, and Grb2 as well as backbone GST protein were prepared as described previously (Swope and Huganir, 1993).

Pervanadate preparation. Sodium pervanadate was prepared as described previously (Meier et al., 1995).

Quantification of Western analysis. Analysis of Western blots was performed by scanning exposed films in transmittance mode and quantifying the digital data with a GS-710 Imaging Densitometer and Multianalyst software (Bio-Rad, Hercules, CA). The integrated optical density (O.D.) for the area of each band, stated as volume or O.D. $\times$ area and here abbreviated as O.D., was determined using Multianalyst software. To determine the linear range of Biomax film and HyperFilm ECL, serial dilutions of several proteins, including MuSK, Src, Fyn, and AchR, were transferred to PVDF, probed with an appropriate antibody, reacted with ECL reagent, and exposed to film. The O.D. versus dilution factor was plotted; O.D. values between 0.2 and 10 were linear for both Biomax film and HyperFilm ECL. Thus, quantification was performed using bands that were not saturated and had O.D. values within this range. All data for coimmunoprecipitation and phosphorylation experiments were normalized for random variability in the level of recovered protein. To analyze changes in coimmunoprecipitation, the O.D. for the coprecipitated protein was normalized for the immunoprecipitated protein. For example, coprecipitation of Src with MuSK was corrected for the amount of MuSK immunoprecipitated (see Fig. $1 A$ ). Normalization for all of the coimmunoprecipitations of Figures 1 and 2 was performed in the same manner. Likewise, analysis of phosphorylation was corrected for any variability in isolation of the phosphorylated protein or kinase. Thus, the O.D. from the anti-phosphotyrosine signal was divided by the antiprotein O.D. for MuSK and AChR, whereas enolase phosphorylation was normalized for the amount of kinase isolated. For Src and Fyn autophosphorylation, the O.D. from the anti-PY ${ }^{416} \mathrm{Src}$ antibody was divided by the anti-Src or anti-Fyn O.D. This normalization corrected for random variability in the expression and immunoprecipitation of each specific protein. Each experiment was performed three times, unless indicated otherwise. Data are expressed as the mean \pm SEM for $n \geq 3$. Except for Figures $8 C$ and $9 E$, all Figures represent the data of a single representative experiment.

Protein determinations. Protein concentrations were determined by the method of Lowry using BSA as a standard (Lowry et al., 1951).

\section{RESULTS}

\section{Association of Src-class kinases with MuSK}

To test for a relationship between Src-class kinases and MuSK, complex formation between these two types of kinases was examined initially. C2 myotube proteins were solubilized under mild conditions of $1 \%$ Triton lysis buffer to maintain proteinprotein interactions and immunoprecipitated with MuSK-specific antibodies. When the precipitates were analyzed for Src by Western blotting, there was specific coimmunoprecipitation of Src with MuSK compared with empty beads (Fig. $1 A$, lane 2 vs 4 ). In a similar manner, Fyn was specifically coimmunoprecipitated with MuSK as demonstrated with a Fyn-specific antibody in Western analysis of the anti-MuSK immunoprecipitates and control beads (Fig. 1B, lane 2 vs 4 ). Activation of other receptor tyrosine kinases, such as the PDGF receptor, results in binding of Src-class kinases (Claesson-Welsh, 1994). In fact, the trkB receptor kinase, which is closely related to MuSK, binds Fyn (Iwasaki et al., 1998). Therefore, whether activation of MuSK by agrin enhanced association of MuSK with Src and Fyn was tested. Treatment of C2 cells for $1 \mathrm{hr}$ with agrin increased complex formation between MuSK and both Fyn and Src (Fig. $1 A, B$, lane 1 vs 2). The percentage of each kinase complexed with MuSK was determined 

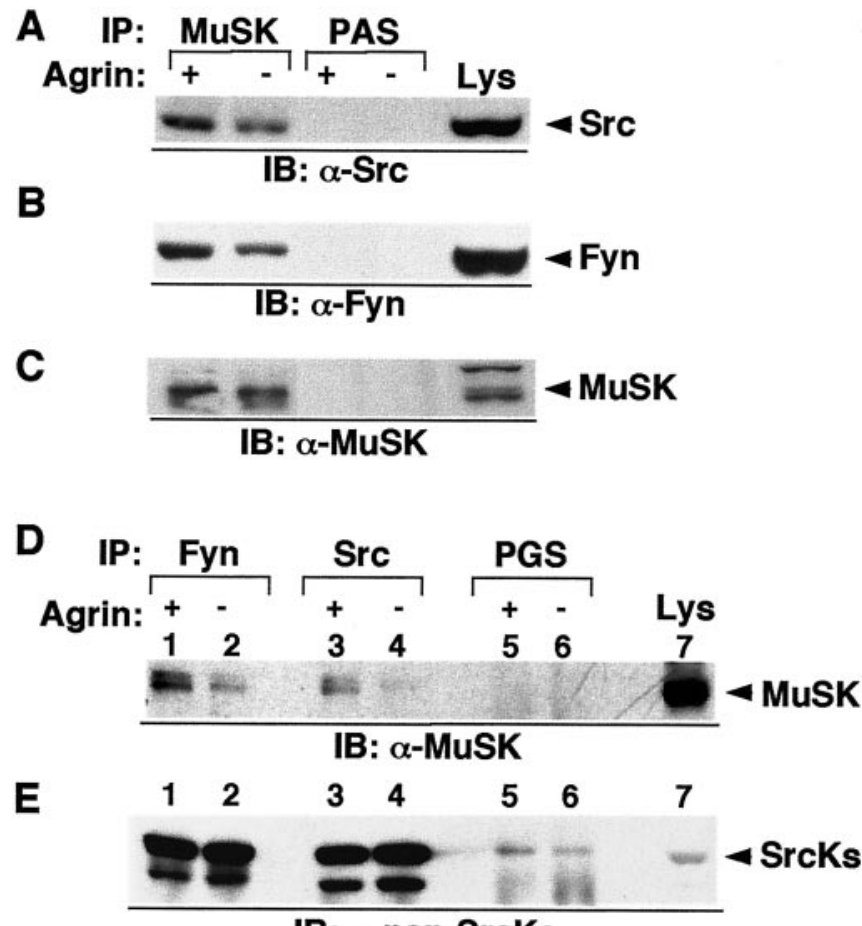

IB: $\alpha$-pan-SrcKs

Figure 1. Effect of agrin on coimmunoprecipitation of MuSK with Fyn and Src. $A, \mathrm{C} 2$ myotubes were treated with $100 \mathrm{pM}$ agrin $($ Agrin +$)$ or an equal volume of conditioned medium vehicle $($ Agrin -$)$ for $1 \mathrm{hr}$. Myotubes were solubilized in lysis buffer and centrifuged, and supernatants representing $90 \%$ of a $100 \mathrm{~mm}$ plate were immunoprecipitated with a mixture of goat polyclonal anti-MuSK antibodies, N19 and C19 (MuSK), or empty protein A-Sepharose $(P A S)$. The immunoprecipitates and $100 \mu \mathrm{g}$ of lysate supernatant after centrif ugation (Lys) were resolved by $8 \%$ SDS-PAGE and analyzed by Western blotting using anti-Src antibody GD11 $(\alpha-S r c)$. $B$, The blot from $A$ was stripped and reanalyzed by Western blotting using anti-Fyn antibody Fyn3 $(\alpha-F y n)$. $C$, The blot from $A$ was stripped and reanalyzed by Western blotting using anti-MuSK-ZH antibody $(\alpha-$ $M u S K) . D, C 2$ myotubes were treated with agrin or conditioned medium vehicle and solubilized as in $A$. The supernatants after centrifugation were immunoprecipitated with anti-Fyn antibody Fyn15 (Fyn), anti-Src antibody Ab-1 (Src), or empty protein G-Sepharose $(P G S)$. The immunoprecipitates and $100 \mu \mathrm{g}$ of lysate supernatant after centrif ugation (Lys) were resolved by $7 \%$ SDS-PAGE and analyzed by Western blotting using anti-MuSK-ZH antibody $(\alpha-M u S K)$. $E$, The blot from $D$ was stripped and reanalyzed by Western blotting with anti-Src-family kinase antibody $\mathrm{Src} 2$ $(\alpha-p a n-S r c k s)$. In $A-E$, an arrowhead indicates the position of Src, Fyn, MuSK, MuSK, and Src-class kinases, respectively.

by comparing the Src and Fyn signal in the MuSK immunoprecipitate with an aliquot of lysed cells. Densitometry scanning quantification, with normalization for recovery of MuSK, was performed to determine the percentage of Src and Fyn complexed with MuSK. In the absence of agrin, the percentage of total Src and Fyn precipitated with MuSK was $1.7 \pm 0.2$ and $2.10 \pm 0.08 \%$, respectively. After agrin treatment, the percentage of Src coimmunoprecipitated was increased to $3.26 \pm 0.09 \%$ over nontreated cells $(p<0.05)$, whereas the percentage of Fyn was increased to $3.8 \pm 0.3 \%(p<0.025)$. For both kinases, an enhancement of association with MuSK in response to agrin occurred in every experiment. The average percentage increase in association of Fyn and Src with MuSK caused by agrin was $80 \pm 20$ and $110 \pm 50 \%$, respectively. These data indicated that Src and Fyn were in a complex with MuSK and that this association was stimulated by agrin.

The existence of this complex was further tested by the recip- rocal experiment. Fyn and Src immunoprecipitates were isolated from C2 myotubes and analyzed for MuSK. MuSK was coimmunoprecipitated with both Fyn and Src but not precipitated by empty beads (Fig. $1 D$, lanes 2 and 4 vs 6 ). By comparing with an aliquot of lysate (Fig. 1D, lane 7), the percentage of MuSK complexed with Fyn and Src was calculated to be $1.6 \pm 0.3$ and $1.3 \pm 0.3 \%$, respectively. Agrin also affected the coimmunoprecipitation of MuSK with Fyn and Src (Fig. 1D, lane 1 vs 2 and lane 3 vs 4 ). After treatment of C2 cells with agrin, the percentage of MuSK precipitated with Fyn rose to $2.8 \pm 0.6 \%(p<0.05)$, and the percentage precipitated with Src rose to $2.0 \pm 0.4 \%(p<$ 0.025). In three experiments, agrin enhanced association of MuSK with Fyn and Src, $80 \pm 20$ and $57 \pm 5 \%$, respectively. These data provided strong evidence that in $\mathrm{C} 2$ myotubes, Fyn and Src were complexed with MuSK under control conditions and that association was stimulated further by agrin.

Because Fyn, Src, and MuSK are all protein tyrosine kinases, the effect of increasing phosphorylation on complex formation was examined. Treatment of $\mathrm{C} 2$ cells with pervanadate, an inhibitor of protein tyrosine phosphatases (Huyer et al., 1997), resulted in a dramatic increase in protein tyrosine phosphorylation, indicating constitutive phosphorylation and dephosphorylation in C2 myotubes (A. S. Mohamed and S. L. Swope, unpublished results). To examine the effect of phosphorylation on association of MuSK and Src-class kinases, myotubes were treated under control conditions or with pervanadate, and MuSK was immunoprecipitated from the lysates. Src-class kinase(s) was specifically coprecipitated with MuSK as demonstrated by analysis of the MuSK precipitates by Western blotting using a pan-Src-class kinase antibody (Fig. $2 A$, lane 2 vs 8 ). Coimmunoprecipitation of the Src-class kinase(s) with MuSK was enhanced by treatment with pervanadate (Fig. $2 A$, lane 1 vs 2 ). In two experiments, inhibition of protein tyrosine dephosphorylation increased the coimmunoprecipitation of Srcclass kinases with MuSK from $1.35 \pm 0.03$ to $2.8 \pm 0.1 \%$, and in a third experiment the increase was from 3.8 to $7.3 \%$. Thus, all three experiments showed an increase in complex formation between Src kinases and MuSK by pervanadate treatment, with an average increase of $117 \pm 6 \%$. The reverse analysis was also performed. Fyn and Src were immunoprecipitated from control and pervanadate-treated myotubes, and the precipitates were analyzed for MuSK. Pervanadate treatment increased coimmunoprecipitation of MuSK with Fyn (Fig. 2B, lane 1 vs 2). The percentage of MuSK associated with Fyn in control and pervanadate-treated cells was $1.4 \pm 0.2$ and $2.6 \pm 0.4 \%(p<$ $0.025)$, respectively. Stimulation of complex formation by pervanadate occurred in every experiment, and the mean increase was $88 \pm 9 \%$. The association of MuSK with Src was also reproducibly increased by a pervanadate treatment (Fig. $2 B$, lane 3 vs 4 ). The percentage of MuSK precipitated with Src increased from $1.01 \pm 0.06$ to $2.4 \pm+0.2 \%$ ( $p<0.025)$, with an average increase of $140 \pm 20 \%$. These data suggested that in C2 cells, association of MuSK with Src and Fyn was being repressed by a constitutively active protein tyrosine phosphatase and was enhanced by increased phosphorylation when the phosphatase was inhibited.

Association between receptor kinases, such as the PDGF receptor, and Src-class kinases is mediated by a phosphotyrosine-SH2 domain interaction. Because association of MuSK and Src-class kinases was enhanced by increased tyrosine phosphorylation, it was predicted that MuSK might bind with the $\mathrm{SH} 2$ domains of Fyn and Src. To test this possibility, fusion protein affinity chromatography was used. $\mathrm{SH} 2$ domain-containing fusion 


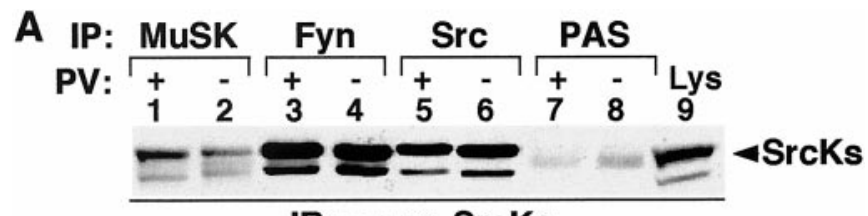

IB: $\alpha$-pan-SrcKs

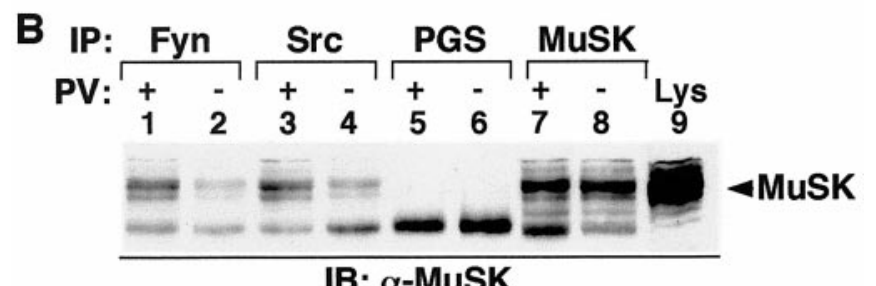

Figure 2. Effect of pervanadate on coimmunoprecipitation of MuSK with Fyn and Src. $A, \mathrm{C} 2$ myotubes were treated with $(P V+)$ or without $(P V-) 30 \mu \mathrm{M}$ pervanadate for $30 \mathrm{~min}$. Myotubes were solubilized in lysis buffer and centrifuged, and supernatants representing $90 \%$ of a $100 \mathrm{~mm}$ plate were immunoprecipitated with a mixture of anti-MuSK antibodies N19 and C19 (MuSK), anti-Fyn antibody Fyn15 (Fyn), anti-Src antibody Ab-1 $(S r c)$, or empty protein A-Sepharose $(P A S)$. The immunoprecipitates and $100 \mu \mathrm{g}$ of lysate supernatant after centrifugation (Lys) were resolved by $8 \%$ SDS-PAGE and analyzed by Western blotting using anti-Src-family kinase antibody Src2 (pan-Srcks). B, C2 myotubes were treated with $(P V+)$ or without $(P V-)$ pervanadate and solubilized as in $A$. The supernatants after centrifugation were immunoprecipitated with anti-Fyn antibody Fyn15 (Fyn), anti-Src antibody Ab-1 (Src), a mixture of anti-MuSK antibodies $\mathrm{N} 19$ and $\mathrm{C} 19(\mathrm{MuSK})$, or empty protein G-Sepharose beads $(P G S)$. The immunoprecipitates and $100 \mu \mathrm{g}$ of lysate supernatant after centrifugation ( $L y s)$ were resolved by $7 \%$ SDS-PAGE and analyzed by Western blotting using anti-MuSK-ZH antibody $(\alpha-$ $M u S K)$. In $A$ and $B$, an arrowhead indicates the position of Src-class kinases and MuSK, respectively.

proteins derived from Fyn, Src, and Grb2 were incubated with myc-tagged MuSK solubilized from heterologous transfected QT-6 fibroblasts. MuSK bound to the Fyn and Src SH2 domain fusion proteins as detected by anti-myc Western analysis (Fig. $3 A$ ). The binding was specific in that MuSK did not bind to backbone fusion protein or the Grb2 $\mathrm{SH} 2$ fusion protein. In addition, MuSK did not bind to the SH3 domains of Fyn or Src (J. R. Kraas and S. L. Swope, unpublished results). Because MuSK was solubilized under extremely stringent conditions of $2 \%$ SDS lysis buffer, which promotes dissociation of protein complexes, these data suggested that MuSK bound directly to the Fyn and Src SH2 domain fusion proteins. However, an indirect interaction cannot be ruled out.

The concentration-dependence for binding of MuSK to the Fyn and Src SH2 domains was analyzed. Increasing concentrations of Fyn and Src SH2 domain fusion proteins, $0.3-30 \mu \mathrm{g}$, were incubated with solubilized myc-tagged MuSK. MuSK bound slightly better to the Src SH2 domain (Fig. 3B). These data suggested that association of MuSK with Fyn and Src was mediated by binding of the Src-class kinases' $\mathrm{SH} 2$ domains to the receptor tyrosine kinase and that MuSK bound with a slightly higher affinity to Src.

Receptor tyrosine kinases bind Src-class kinases via phosphotyrosine motifs on the receptors. In vivo, these tyrosines are phosphorylated by ligand-induced dimerization and auto/ transphosphorylation of the receptor tyrosine kinases (ClaessonWelsh, 1994; Thomas and Brugge, 1997). Whether the binding of MuSK to the SH2 domain fusion protein of Src-class kinases was dependent on MuSK transphosphorylation was tested using a
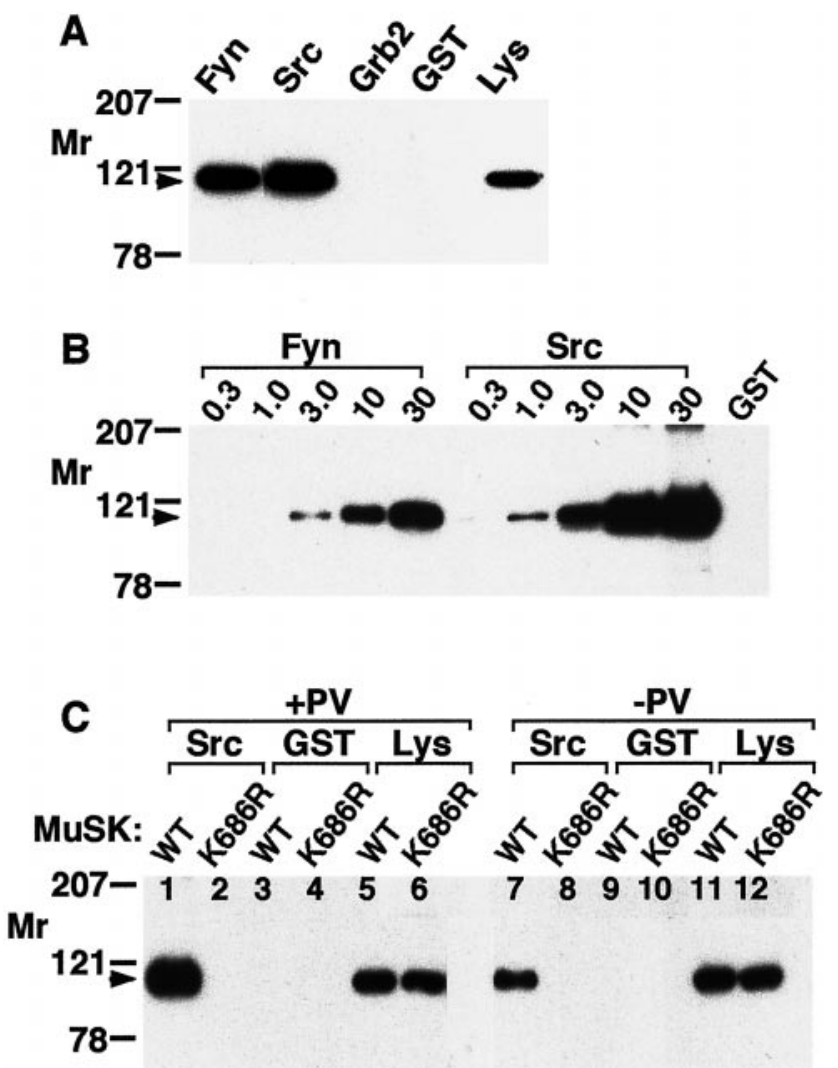

Figure 3. Direct binding of MuSK to the SH2 domains of Fyn and Src. QT-6 cells were transfected with pBK-CMV-mycMuSK $[A-C(W T)]$ or pBK-CMV-mycMuSK[K686R] [C $(K 686 R)]$. Forty-eight hours after transfection, cells were treated for $10 \mathrm{~min}$ with $20 \mu \mathrm{M}$ pervanadate $(A, B)$, then solubilized with $2 \%$ SDS lysis buffer and diluted to $0.4 \%$ SDS $/ 2 \%$ Triton X-100 as described in Materials and Methods. A, Lysates representing cells from $100 \%$ of a $100 \mathrm{~mm}$ dish were incubated at $4^{\circ} \mathrm{C}$ for $3 \mathrm{hr}$ with $10 \mu \mathrm{g}$ of a Fyn (Fyn), Src (Src), or Grb2 (Grb2) fusion protein or backbone (GST) protein. B, Lysates representing cells from $100 \%$ of a $100 \mathrm{~mm}$ dish were incubated at $4^{\circ} \mathrm{C}$ for $3 \mathrm{hr}$ with $0.3-30 \mu \mathrm{g}$ of Fyn (Fyn) or Src (Src) SH2 domain fusion protein or $30 \mu \mathrm{g}$ of backbone protein $(G S T) . C$, Before solubilization, cells were treated with $(+P V)$ or without $(-P V)$ pervanadate as in $A$ and $B$. Lysates representing cells from $100 \%$ of a $100 \mathrm{~mm}$ dish transfected with pBK-CMV-mycMuSK $(W T)$ or pBK$\mathrm{CMV}$-mycMuSK[K686R] $(\mathrm{K} 686 R)$ were incubated at $4^{\circ} \mathrm{C}$ for $3 \mathrm{hr}$ with 10 $\mu \mathrm{g}$ of a Src SH2 fusion protein $(S r c)$ or backbone protein $(G S T)$. In $A-C$, bound proteins and an aliquot of the lysate representing $1.5 \%$ of a $100 \mathrm{~mm}$ dish (Lys) were resolved by 7\% SDS-PAGE gel and analyzed by Western blotting using 9E10 anti-myc antibody. Molecular weight markers, in kilodaltons, are indicated on the left. In $A-C$, an arrowhead indicates myc-MuSK.

catalytically inactive MuSK construct containing a lysine to arginine point mutation (MuSK[K686R]) (Gillespie et al., 1996). First, whether MuSK autophosphorylation in the QT6 cells occurred was determined by testing whether MuSK[K686R] could be a substrate for wild-type MuSK. In fact, myc-tagged MuSK[K686R] was phosphorylated when coexpressed with nontagged wild-type mouse MuSK, but not when expressed alone (data not shown). Thus, wild-type MuSK was capable of auto/ transphosphorylation in this system.

The catalytically inactive MuSK[K686R] was used to test whether binding to the SH2 domain of Src was dependent on autophosphorylation. Heterologous cells expressing the wild type or MuSK[K686R] were treated without or with pervanadate to inhibit dephosphorylation and then solubilized. Lysates were in- 
cubated with the Src SH2 domain fusion protein and binding of myc-tagged wild type or MuSK[K686R] was determined by antimyc Western analysis. In the absence of pervanadate treatment, wild-type MuSK bound to the $\mathrm{Src} \mathrm{SH} 2$ domain but MuSK[K686R] did not (Fig. 3C, lane 7 vs 8). This absence of binding was not caused by altered expression of the inactive MuSK because analysis of the lysates demonstrated that both wild type and MuSK[K686R] were expressed (Fig. 3C, lanes 11 and 12). Treatment of the cells expressing wild-type MuSK with pervanadate to block dephosphorylation caused an increase in the binding of wild-type MuSK to the Src SH2 domain fusion protein (Fig. $3 C$, lane 1 vs 7). However, after treatment with pervanadate, binding of MuSK[K686R] was still not detected (Fig. 3C, lane 2). Analysis of the lysates demonstrated that the expression levels of wild type and MuSK[K686R] were unaffected by pervanadate (Fig. $3 C$, lanes 5 and 6 vs 11 and 12). These data indicated that binding of the wild-type MuSK to the SH2 domain fusion protein was dependent on tyrosine phosphorylation of MuSK. In addition, the phosphorylation was attributable to autophosphorylation of MuSK because catalytically inactive MuSK was unable to bind to the $\mathrm{SH} 2$ domain fusion protein.

\section{Phosphorylation of MuSK and the AChR by Src-class kinases}

A mechanism for reciprocal regulation between receptor and Src-class kinases has been elucidated in other systems. Ligandactivated autophosphorylation of receptor tyrosine kinases results in binding of Src-class kinases via their SH2 domains. This binding leads to phosphorylation of the receptor kinase by Srcclass kinases and thus creates binding sites on the receptor for an additional SH2 domain containing enzymes and adapter proteins (Claesson-Welsh, 1994). As described above and by others, MuSK does autophosphorylate (Gillespie et al., 1996). Whether MuSK could be a substrate for Src and Fyn was tested next. For this analysis, the myc-tagged MuSK[K686R] was coexpressed with Src and Fyn in a heterologous cell line. Because MuSK was not catalytically active, any MuSK phosphorylation could not be caused by autophosphorylation. In fact, when MuSK[K686R] was expressed alone and then immunoprecipitated with anti-myc antibody, no phosphorylation was observed, as demonstrated by phosphotyrosine Western blotting (Fig. 4A, lane 7); however, when coexpressed with $\mathrm{Src}$, MuSK[K686R] was phosphorylated (Fig. $4 A$, lane 1 ). Some random variability in the isolation of MuSK occurred (Fig. 4B, lanes 1-8); however, changes in the amounts of MuSK precipitated could not account for the "all" or nothing phosphorylation of MuSK[K686R] in the presence or absence of Src, respectively (Fig. $4 A, B$, lane 1 vs 7 ). Isolation of MuSK was dependent on transfection with the MuSK[K686R] plasmid because MuSK could not be precipitated from control cells transfected with empty plasmid (Fig. 4B, lane 10). Thus, catalytically inactive MuSK could be phosphorylated upon coexpression with Src.

Phosphorylation of MuSK by Fyn was also tested. In this transfection system, the activity of expressed Fyn is low, but Fyn activity can be increased by rapsyn (Mohamed and Swope, 1999). In fact, phosphorylation of MuSK via Fyn was observed only after coexpression of rapsyn (Fig. $4 A$, lane 3 vs 4 ). In two of three experiments, phosphorylation of MuSK by Src was also potentiated by rapsyn. We tested whether the phosphorylation of MuSK was specific for Src-family kinases. Btk, a non-receptor kinase distinct from but related to the Src-family, mediated little or no phosphorylation of MuSK, demonstrating the specificity of the

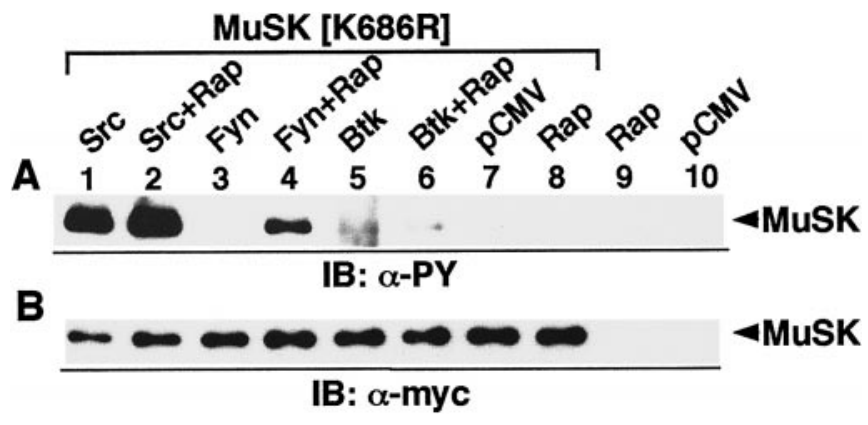

Figure 4. Phosphorylation of MuSK by Src and Fyn. QT-6 cells were transfected with pBK-CMV-mycMuSK[K686R] and Src (Src), Fyn (Fyn), or Bruton's tyrosine kinase $(B t k)$ in the absence or presence of rapsyn (Rap). Replicate control cultures were transfected with rapsyn or empty vector $(p C M V)$ alone. After $40 \mathrm{hr}$, the cells were solubilized with $2 \%$ SDS lysis buffer, diluted to $0.4 \%$ SDS/2\% Triton X-100, and MuSK immunoprecipitated from lysate representing $90 \%$ of a $100 \mathrm{~mm}$ plate using an anti-myc antibody $\mathrm{JH} 2235$. Immunoprecipitates were resolved by $8 \%$ SDS-PAGE and analyzed by immunoblotting with $(A)$ antiphosphotyrosine antibodies 4G10 and PY99 $(\alpha-P Y)$ and $(B)$ anti-myc antibody 9E10 $(\alpha-m y c)$.

effect of Src and Fyn (Fig. 4A, lanes 5 and 6). These data supported the idea that MuSK can be phosphorylated by Src and Fyn and in addition suggested that MuSK is a substrate for these kinases in muscle.

Whether Fyn and Src phosphorylate MuSK in muscle cells was examined pharmacologically. PP1 is a highly selective Src-class kinase inhibitor. Depending on the specific Src family kinase and the cell type examined, PP1 has $\mathrm{ID}_{50}$ values of $10-100 \mathrm{~nm}$ in vitro and 0.5-30 $\mu \mathrm{M}$ in intact cells (Hanke et al., 1996; Liu et al., 1999). First, inhibition of Fyn and Src by PP1 in C2 myotubes was demonstrated. Activation of Src-class kinases results in auto/ transphosphorylation at $\mathrm{Y}^{416}$ (chicken Src numbering) within the catalytic domain (Thomas and Brugge, 1997). Thus, phosphorylation at this site can be used as a measure of activation. We developed an anti-Y $\mathrm{Y}^{416}$ phosphorylation state-specific antibody, GW001, to examine the activity of Src-class kinases by Western blotting, as described in Materials and Methods. The ability of PP1 to inhibit Src and Fyn activities in C2 cells was analyzed using the anti-PY ${ }^{416}$ Src antibodies. The $\mathrm{Y}^{416}$ phosphorylation of Fyn and Src immunoprecipitated from control C2 myotubes was low (Fig. 5A, lanes 1 and 5). Treatment of $\mathrm{C} 2$ myotubes with pervanadate increased the phosphorylation of Fyn and Src on $\mathrm{Y}^{416}$ (Fig. 5A, top panel, lane 1 vs 2 and lane 5 vs 6 ). Thus, pervanadate revealed constitutive activity and autophosphorylation of Fyn and Src. Pretreatment of myotubes with 10 or $20 \mu \mathrm{M}$ PP1 inhibited the pervanadate-induced increase in $\mathrm{Y}^{416}$ phosphorylation on Fyn and Src (Fig. 5A, lane 2 vs 3 and 4 and lane 6 vs 7 and 8 ). The changes in anti-PY ${ }^{416}$ Src signal could not be explained by alterations in the isolation of Fyn and Src (Fig. $5 A$, bottom panel). Upon normalization for the amount of kinase isolated, Fyn autophosphorylation/activity was found to be $75 \pm$ 7 and $90 \pm 2 \%$ with 10 and $20 \mu \mathrm{M}$ PP1, respectively. Src activity was inhibited by $60 \pm 10$ and $60 \pm 10 \%$ with 10 and $20 \mu \mathrm{M} \mathrm{PP} 1$, respectively. The higher sensitivity of Fyn to PP1, compared with Src, agreed with a previous report (Hanke et al., 1996). These data demonstrated that as measured by autophosphorylation, PP1 blocked the activity of Fyn and Src in C2 myotubes.

To reveal constitutive phosphorylation of MuSK by Src-class kinases, pervanadate and PP1 were also used. C2 myotubes were treated with pervanadate, and endogenous MuSK phosphoryla- 

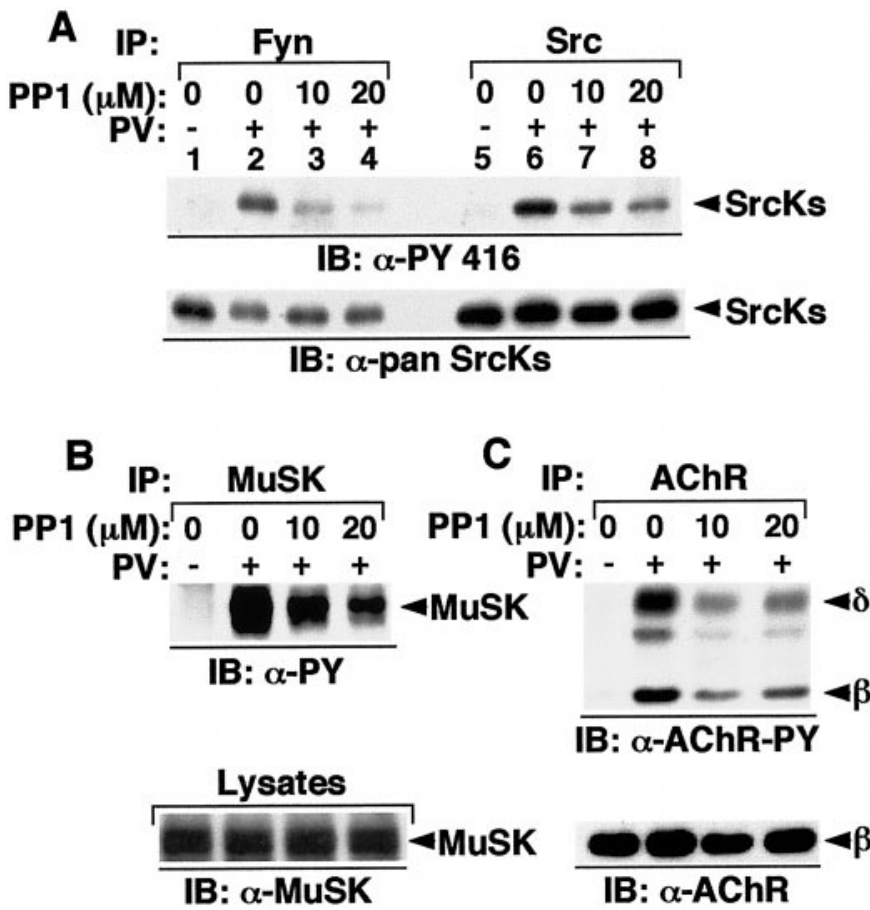

Figure 5. Effect of inhibiting Src-class kinases on pervanadate-induced MuSK and AChR phosphorylation in vivo. A, $\mathrm{C} 2$ myotubes were treated with 10 or $20 \mu \mathrm{M}$ PP1 or vehicle for $1 \mathrm{hr}$ followed by treatment with $(P V$ $+)$ or without $(P V-) 30 \mu \mathrm{M}$ pervanadate for $10 \mathrm{~min}$. Myotubes were solubilized in RIPA buffer and centrifuged, and supernatants representing $20 \%$ of a $60 \mathrm{~mm}$ dish were immunoprecipitated with Fyn antibody Fyn15 (Fyn) or Src antibody Ab-1 (Src). The immunoprecipitates were resolved by $8 \%$ SDS-PAGE and analyzed by Western blotting using phosphorylation state-specific anti-Src-class kinase antibody GW001 $(\alpha-P Y 416)$ (top panel). The PY416 blot was stripped and reanalyzed by Western blotting using anti-Src-class kinase antibody Src2 (pan Srcks) (bottom panel). B, Supernatants representing $20 \%$ of a $60 \mathrm{~mm}$ dish as in $A$ were immunoprecipitated with anti-MuSK antibody GW002 (MuSK). The immunoprecipitates were resolved by $7 \%$ SDS-PAGE and analyzed by Western blotting using a mixture of anti-phosphotyrosine antibodies $4 \mathrm{G} 10$ and PY99 ( $\alpha-P Y)$ (top panel). Supernatants representing $1 \%$ of a 60 $\mathrm{mm}$ dish were resolved by $7 \%$ SDS-PAGE and analyzed by Western blotting using anti-MuSK antibody $\alpha$-MuSK-ZH $(\alpha-M u S K)$ (bottom panel). $C$, Supernatants representing $20 \%$ of a $60 \mathrm{~mm}$ dish as in $A$ were immunoprecipitated with anti-AChR antibody $88 \mathrm{~b}(A C h R)$. The immunoprecipitates were resolved by $8 \%$ SDS-PAGE and analyzed by Western blotting using a mixture of the phosphorylation state-specific anti-AChR $\beta$ subunit (JH1360) and anti-AChR $\delta$ subunit (JH1358) antibodies $(\alpha-$ $A C h R-P Y$ ) (top panel). The top blot from $C$ was stripped and reanalyzed by Western blotting using the AChR $\beta$ subunit antibody mAb $148(\alpha-$ $A C h R)$ (bottom panel). In $A-C$, an arrowhead indicates the position of Src-class kinases, MuSK, and AChR $\beta$ and $\delta$ subunits, respectively.

tion was examined by immunoprecipitation and Western blotting. Tyrosine phosphorylation of MuSK was essentially undetectable in control cells, whereas pervanadate treatment resulted in a striking increase in MuSK phosphorylation (Fig. 5B, lane 1 vs 2). Incubation of C2 cells with PP1 inhibited pervanadate-induced MuSK phosphorylation (Fig. 5B, lane 2 vs 3 and 4 ). In each of three experiments, PP1 at $20 \mu \mathrm{M}$ was slightly more effective than at $10 \mu \mathrm{M}$. Inhibition of pervanadate-induced MuSK phosphorylation by 10 and $20 \mu \mathrm{M}$ PP1 was $50 \pm 10$ and $60 \pm 10 \%$, respectively. Neither pervanadate nor PP1 affected MuSK expression (Fig. 5B, bottom panel). The effect of PP1 suggested that approximately half of the induced phosphorylation of MuSK was caused by Src-class kinases.

One of the major goals of this study was to determine whether
Src-class kinases phosphorylate and regulate AChRs of skeletal muscle. Phosphorylation of the AChR by Src and Fyn was also tested pharmacologically. Once again, C2 cells were treated with or without pervanadate and PP1. AChRs were immunoprecipitated and tyrosine phosphorylation was examined using phosphorylation state-specific anti- $\beta$ and anti- $\delta$ subunit antibodies. AChR phosphorylation was low in control cells, whereas pervanadate dramatically increased receptor phosphorylation (Fig. $5 C$, lane 1 vs 2). When we corrected for recovery of AChRs (Fig. 5C, bottom panel ), a 22- to 26-fold increase in phosphorylation of the $\beta$ subunit and a 10- to 130-fold increase in phosphorylation of the $\delta$ subunit occurred. This phosphorylation appeared to be attributable, in part, to Src-class kinases, as demonstrated by inhibition with PP1 (Fig. 5C, lane 2 vs 3 and 4). Cells pretreated with 10 and $20 \mu \mathrm{M}$ PP1 showed a $60 \pm 7$ and $70 \pm 10 \%$ inhibition of pervanadate-induced $\beta$ subunit phosphorylation, respectively. Inhibition of $\delta$ subunit phosphorylation was $54 \pm 4$ and $72 \pm 7 \%$ by 10 and $20 \mu \mathrm{M}$ PP1, respectively. Therefore, phosphorylation of AChRs by Src-class kinases occurred in $\mathrm{C} 2$ cells.

MuSK phosphorylation in C2 myotubes was inhibited by PP1 (Fig. 5B). These data suggested that Src-class kinases phosphorylated MuSK in muscle cells. However, because MuSK autophosphorylates, the effect of PP1 on MuSK might have been to inhibit autophosphorylation. Whether PP1 could block MuSK kinase activity in vitro was used to further test the conclusion that MuSK was phosphorylated by Src kinases in C2 cells. C2 myotubes were treated with or without pervanadate, MuSK was immunoprecipitated, and MuSK activity was analyzed in vitro using enolase as a substrate (Fig. 6A). Phosphorylation of both MuSK and enolase was detected by anti-phosphotyrosine immunoblotting. In control cells, no phosphorylation of MuSK or enolase was observed (Fig. $6 A$, top and bottom panels, lane 2). Pervanadate treatment caused a striking increase in both MuSK and enolase phosphorylation (Fig. 6A, top and bottom panels, lane 1). Phosphorylation of enolase occurred in vitro because it was dependent on ATP in the reaction (Fig. $6 \mathrm{~A}$, bottom panel, lane 3 ). In contrast, MuSK phosphorylation was independent of ATP in the in vitro reaction, demonstrating that MuSK phosphorylation occurred in the intact myotubes (Fig. 6A, top panel, lane 1 vs 3 ). As expected, inclusion of 1 or $5 \mu \mathrm{M}$ PP1 in the in vitro reaction did not affect the in vivo phosphorylation of MuSK (Fig. 6A, top panel, lane 1 vs 4 and 6 ). In addition, enolase phosphorylation by MuSK was not affected by 1 or $5 \mu \mathrm{M}$ PP1 added to the in vitro reaction (Fig. $6 A$, bottom panel, lane 1 vs 4 and 6 ). The phosphorylation of enolase in the presence of 10 and $20 \mu \mathrm{M}$ PP1 was $96 \pm 4$ and $104 \pm 5 \%$, respectively, of the level in the absence of PP1. These data demonstrated that PP1 did not directly inhibit the enzymatic activity of MuSK.

In contrast, PP1 did block the enzymatic activity of Fyn and Src in vitro. Using the same paradigm, myotubes were treated with or without pervanadate, Fyn and Src were isolated, and in vitro phosphorylation of enolase in the presence or absence of PP1 was determined. Pervanadate treatment of the myotubes stimulated in vitro phosphorylation of enolase by both Fyn and Src (Fig. 6B, top panel, lane 1 vs 2 and lane 8 vs 9). The phosphorylation of enolase by Fyn and Src occurred in vitro because it was dependent on ATP in the reaction (Fig. 6B, lane 1 vs 3 and lane 8 vs 10). Fynmediated phosphorylation of enolase was inhibited by PP1 (Fig. $6 B$, lane 1 vs 4 and 6 ). Fyn activity was inhibited in vitro by $69 \pm$ 5 and $96 \pm 4 \%$ with 1 and $5 \mu \mathrm{M}$ PP1, respectively. Similarly, Src activity was inhibited by $91 \pm 1$ and $100 \pm 1 \%$ with 1 and $5 \mu \mathrm{M}$ PP1, respectively (Fig. $6 B$, lane 8 vs 11 and 13). These data 
A

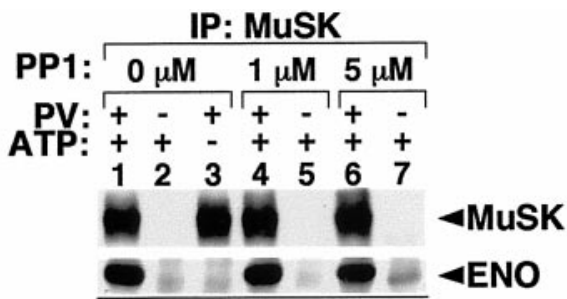

IB: $\alpha-P Y$

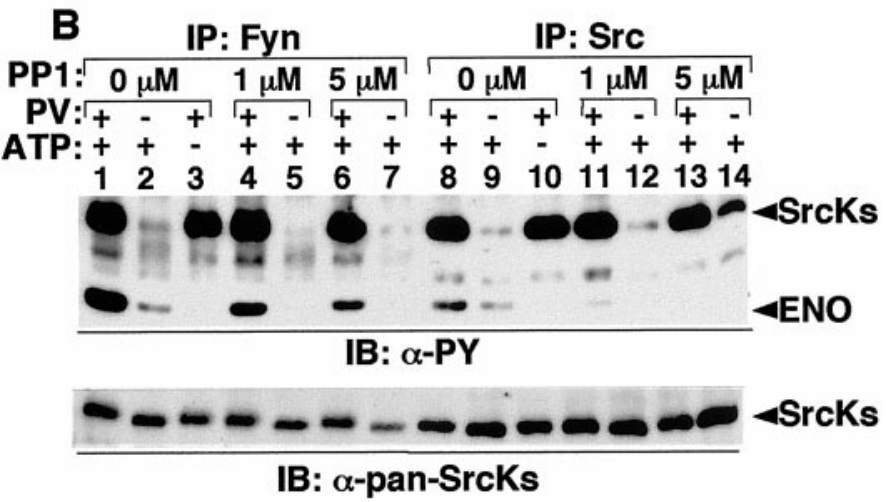

Figure 6. Effect of inhibiting Src-class kinases on Fyn, Src, and MuSK kinase activities in vitro. $A, \mathrm{C} 2$ myotubes were treated with pervanadate at $30 \mu \mathrm{M}(P V+)$ or vehicle $(P V-)$ for $30 \mathrm{~min}$. Myotubes were solubilized in RIPA buffer and centrifuged, and supernatants representing $30 \%$ of a 60 $\mathrm{mm}$ dish were immunoprecipitated with anti-MuSK antibody GW002 $(M u S K)$. The kinase activity of immunoprecipitated MuSK was determined with an in vitro kinase assay using enolase as a substrate in the presence of 1 or $5 \mu \mathrm{M}$ PP1 $(P P 1+)$ or vehicle $(P P 1-)$ and the presence $(A T P+)$ or absence $(A T P-)$ of ATP. For examining MuSK phosphorylation, kinase reactions were resolved by $7 \%$ SDS-PAGE and analyzed by Western blotting using anti-phosphotyrosine antibodies 4G10 and PY99 $(\alpha-P Y)($ top panel $)$. Enolase was resolved by $8 \%$ SDS-PAGE and analyzed by Western blotting using anti-phosphotyrosine antibodies 4G10 and PY99 $(\alpha-P Y)$ (bottom panel). Arrowheads indicate the positions of MuSK $(M u S K)$ and enolase (ENO). B, Supernatants from $A$ representing $30 \%$ of a $60 \mathrm{~mm}$ dish were immunoprecipitated with anti-Fyn antibody Fyn 15 (Fyn) or anti-Src antibody Ab-1 (Src). The kinase activities of immunoprecipitated Fyn and Src were determined with an in vitro kinase assay using enolase as substrate as described in $A$. Enolase and Src-class kinases were resolved by $8 \%$ SDS-PAGE and analyzed by Western blotting using anti-phosphotyrosine antibodies 4G10 and PY99 ( $\alpha-P Y)$ (top panel). The blots were stripped and reanalyzed by Western blotting using the pan-Src kinase antibody Src2 ( pan-Srcks) (bottom panel). Arrowheads indicate the positions of enolase $(E N O)$ and Src-class kinases $(\mathrm{SrCKs})$.

demonstrated that the enzymatic activity of Src and Fyn kinases from C2 myotubes was inhibited by PP1, whereas the activity of MuSK was not. Furthermore, these data support the idea that phosphorylation of MuSK and the AChR in C2 myotubes was attributable to Src-class kinases (Fig. 5B,C).

Agrin activates MuSK and induces MuSK phosphorylation (Glass et al., 1996). Whether agrin-stimulated phosphorylation of MuSK was dependent on Src-class kinases was tested. For this experiment, C2 myotubes were treated with agrin, MuSK was immunoprecipitated, and phosphorylation was examined by Western blotting. Agrin induced MuSK phosphorylation (Fig. 7A, lane 1 vs 2). The effect of agrin on MuSK phosphorylation was reduced by PP1 (Fig. 7A, lane 2 vs 3 and 4 ). At 10 and $20 \mu \mathrm{M}, \mathrm{PP} 1$ blocked agrin-stimulated MuSK phosphorylation by $40 \pm 10$ and $69 \pm 6 \%$. These data argue that phosphorylation of MuSK upon agrin treatment was attributable, in part, to Src-class kinases.

Phosphorylation of the AChR in response to agrin does not occur in myotubes derived from a MuSK knock-out mouse (Glass

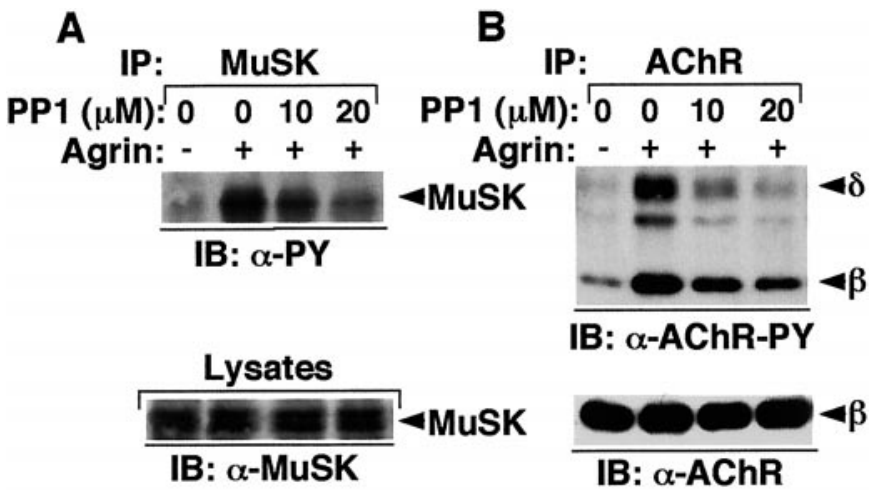

Figure 7. Effect of inhibiting Src-class kinases on agrin-induced MuSK and $\mathrm{AChR}$ phosphorylation in vivo. $A, \mathrm{C} 2$ myotubes were treated with 10 or $20 \mu \mathrm{M}$ PP1 $(P P 1+)$ or vehicle $(P P 1-)$ for $1 \mathrm{hr}$ followed by treatment with $100 \mathrm{pM}$ agrin $(+)$ or conditioned medium vehicle $(-)$ for $10 \mathrm{~min}$. Myotubes were solubilized in RIPA buffer and centrifuged, and supernatants representing $40 \%$ of each $60 \mathrm{~mm}$ dish were immunoprecipitated with anti-MuSK antibody GW002 (MuSK). The immunoprecipitates were resolved by $7 \%$ SDS-PAGE and analyzed by Western blotting using a mixture of anti-phosphotyrosine antibodies 4G10 and PY99 ( $\alpha-P Y)$ (top panel). Supernatants representing $1 \%$ of each $60 \mathrm{~mm}$ dish were resolved by $7 \%$ SDS-PAGE and analyzed by Western blotting with anti-MuSK antibody MuSK-ZH ( $\alpha$-MuSK) (bottom panel). Arrowheads indicate the position of MuSK. $B$, Supernatants representing $40 \%$ of a $60 \mathrm{~mm}$ dish, as in $A$, were used for immunoprecipitation with anti-AChR antibody $88 \mathrm{~b}$ $(A C h R)$. The immunoprecipitates were resolved by $8 \%$ SDS-PAGE and analyzed by Western blotting using a mixture of the phosphorylation state-specific anti-AChR $\beta$ subunit (JH1360) and anti-AChR $\delta$ subunit (JH1358) antibodies $(A C h R)$ (top panel). The blot was stripped and reanalyzed by Western blotting using anti-AChR $\beta$ subunit antibody $\mathrm{mAb}$ $148(A C h R)$ (bottom panel). Arrowheads indicate the positions of the $\operatorname{AChR} \beta$ and $\delta$ subunits.

et al., 1997). Thus, agrin-stimulated phosphorylation of the AChR is dependent on MuSK. Whether agrin-stimulated/ MuSK-mediated AChR phosphorylation was dependent on Srcfamily kinases was examined. C2 myotubes were treated with agrin, AChRs were isolated, and phosphorylation was analyzed by Western blotting using the phosphorylation state anti- $\beta$ and anti- $\delta$ subunit antibodies. Agrin induced AChR phosphorylation (Fig. 7B, lane 1 vs 2). The agrin-stimulated phosphorylation of the AChR was inhibited by PP1 (Fig. 7B, lane 2 vs 3 and 4). The AChR $\beta$ subunit phosphorylation was blocked by $51 \pm 7$ and $69.5 \pm 0.7 \%$ with 10 and $20 \mu \mathrm{M}$ PP1, respectively. The $\delta$ subunit phosphorylation was blocked by $60 \pm 10$ and $74 \pm 8 \%$ with 10 and $20 \mu \mathrm{M}$ PP1, respectively. These data indicated that agrin activated Src-class kinases, resulting in phosphorylation of the AChR in C2 myotubes.

\section{Cytoskeletal anchoring of the AChR by Src-class kinases}

Agrin stimulates AChR anchoring to the cytoskeleton in muscle cells (Wallace, 1992). Anchoring of AChRs is thought to be regulated by tyrosine phosphorylation (Wallace, 1992; Mohamed and Swope, 1999). Because Src-class kinases appeared to mediate the effect of agrin to stimulate AChR phosphorylation (Fig. 7B), a role for these kinases to regulate receptor anchoring was tested. The levels of anchored AChRs were determined by examining the resistance of the receptors to extraction with $0.5 \%$ Triton X-100, an approach previously demonstrated to be useful for analyzing interaction of AChRs with the cytoskeleton (Prives et al., 1982). For this experiment, myotubes were treated with agrin, agrin plus PP1, or vehicle. The cells were then extracted with $0.5 \%$ Triton 
A
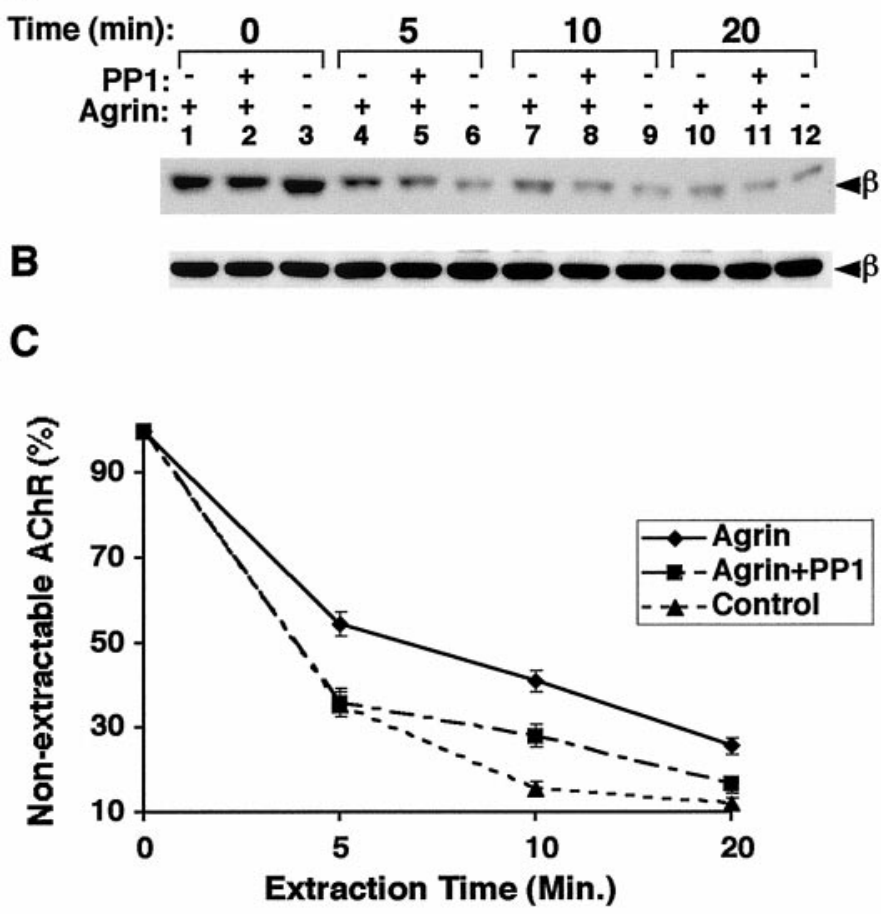

Figure 8. Effect of inhibiting Src-class kinases on agrin-induced AChR cytoskeletal anchoring. $A, \mathrm{C} 2$ myotubes were treated with $20 \mu \mathrm{M}$ PP1 (PP1 $+)$ or DMSO vehicle $(P P 1-)$ for $1 \mathrm{hr}$ followed by treatment with $100 \mathrm{pm}$ agrin $($ Agrin +$)$ or conditioned medium vehicle $($ Agrin -$)$ for $1 \mathrm{hr}$ as indicated. Treated myotubes were extracted with Prives buffer containing $0.5 \%$ Triton X-100 for the indicated times and rinsed once with Prives buffer containing $0.1 \%$ Triton $\mathrm{X}-100$. The proteins remaining on the dish were extracted using SDS-PAGE sample buffer, sonicated, and centrifuged. Aliquots of the SDS-extracted proteins representing $10 \%$ of a 35 $\mathrm{mm}$ dish were resolved by $8 \%$ SDS-PAGE and analyzed by Western blotting using anti-AChR $\beta$ subunit antibody mAb 148. B, Sister C2 cultures were treated with or without agrin, with or without PP1 as in $A$, and treated with Prives buffer without Triton X-100. Dishes were rinsed once with Prives buffer without Triton X-100. The proteins on the dish were extracted using SDS-PAGE sample buffer, sonicated, and centrifuged. SDS-extracted proteins representing $10 \%$ of $35 \mathrm{~mm}$ dishes were resolved by $8 \%$ SDS-PAGE and analyzed by Western blotting using anti-AChR $\beta$ subunit antibody mAb 148. $C$, Four independent experiments as in $A$ were analyzed. C2 myotubes were treated with agrin ( ), agrin $+20 \mu \mathrm{M}$ PP1 $(\boldsymbol{\square})$, or vehicle control $(\mathbf{\Delta})$. The data were quantified by densitometric scanning and represent the mean \pm SEM of the percentage of the total level of AChRs that remained on the dishes after $0.5 \%$ Triton X-100 extraction. In $A$ and $B$, arrowheads indicate the position of the AChR $\beta$ subunit.

X-100 over a time course of $0-20 \mathrm{~min}$. The detergent-resistant cytoskeletal material remaining on the plate was eluted with SDS-PAGE sample buffer and analyzed for AChRs by Western blotting. With no extraction, the levels of total AChRs in the myotubes were similar for all treatments (Fig. 8A, B, lanes 1-3). Thus, neither agrin nor PP1 affected the total amount of receptor. After 5 min of Triton X-100 extraction, little AChR was nonextractable in the control cells (Fig. $8 A$, lane 6 ). Thus, most of the AChRs were soluble and not linked to the cytoskeleton in control cells. However, after agrin treatment, the level of nonextractable AChRs was increased, reflecting agrin-induced cytoskeletal anchoring (Fig. $8 A$, lane 4 vs 6 ). In addition, PP1 partially reversed the action of agrin (Fig. $8 A$, lane 4 vs 5 ). The effect of PP1 could not be explained by an enhanced loss of cells (Fig. $8 B$ ). The same effects of agrin and PP1 were seen at 10 min of Triton X-100 extraction. As expected, most AChRs in control cells were solubilized by 10 min of extraction with Triton X-100 (Fig. 8A, lane 9). In cells treated with agrin, a pool of AChRs continued to be resistant to $10 \mathrm{~min}$ of detergent extraction (Fig. $8 A$, lane 7 ). The pool of receptors resistant to 10 min of extraction was smaller in cells treated with PP1 (Fig. 8A, lane 8 ). The same trend was observed with $20 \mathrm{~min}$ of extraction (Fig. 8A, lanes 11-12). The data in Figure $8 C$ show the reproducibility of this effect. In four experiments, at all time points of Triton X-100 extraction, the levels of AChRs in the nonextractable fraction were enhanced by agrin, and the effect of agrin was significantly reversed by PP1 (Fig. 8C). These data indicated that Src-class kinases mediate at least part of the effect of agrin to induce cytoskeletal anchoring of the AChR in muscle cells. Furthermore, these results support the importance of Src-class kinases in the stabilization of AChRs at the endplate during formation of the NMJ.

\section{Maturation of AChR clustering by Src-class kinases}

Whether the effect of agrin to induce AChR clustering was mediated by Src-class kinases was also examined. Two approaches were used: inhibition of Src kinases with PP1 or expression of a dominant negative Src. C2 myotubes were treated with agrin in the presence or absence of PP1, and AChR clustering was analyzed using tetramethyl(rhodamine)- $\alpha$-bungarotoxin or Texas Red- $\alpha$-bungarotoxin labeling and epifluorescence microscopy. Agrin-induced AChR clustering was still apparent in the presence of PP1 (Fig. 9, $A$ vs $B$ ). However, the size of receptor aggregates was altered by inhibition of Src-class kinases. The size distribution of receptor clusters was analyzed by binning into categories of $<15 \mu \mathrm{m}, 15-25 \mu \mathrm{m}$, and $>25 \mu \mathrm{m}$ (Fig. $9 E,+P P 1$ and $-P P 1)$. The most obvious effect was a loss of large clusters and a dramatic shifting of clusters to sizes $<15 \mu \mathrm{m}$. The percentage of clusters $>25 \mu \mathrm{m}$ in agrin-treated cultures was $57 \pm 3 \%$, $n=5$, whereas after inhibition of Src-class kinases the number was reduced to $4.0 \pm 0.1 \%, n=5$ (Fig. $9 E,-P P 1$ vs $+P P 1$ clear bars $)$. Conversely, the percentage of clusters $<15 \mu \mathrm{m}$ was $13 \pm$ $3 \%$ in control cells and $86 \pm 6 \%, n=5$, in PP1-treated cells (Fig. $9 E,-P P 1$ vs $+P P 1$, hatched bars $)$. These data indicated that inhibition of Src-class kinases with PP1 blocked the formation of large AChR clusters in response to agrin.

The role of Src-class kinases in the maturation of large AChR clusters was corroborated using a dominant negative approach. C2 cells were transfected to express a dominant negative Src and treated with agrin, and AChR clustering was analyzed. Cells expressing the dominant negative Src were identified by staining with a pan-Src kinase antibody, $s r c 2$, whereas AChRs were identified with Texas Red- $\alpha$-bungarotoxin. Again, agrin-induced clustering occurred in cells expressing the dominant negative kinase; however, compared with control cultures transfected with empty plasmid, the size of receptor clusters was reduced by expression of dominant negative Src (Fig. 9, $C$ vs $D$ ). In contrast, expression of GFP did not affect AChR clustering (data not shown). For control cells, $37 \pm 2 \%$ of the clusters were $15-25 \mu \mathrm{m}$ and $33 \pm 3 \%$ were $>25 \mu \mathrm{m}$, whereas $31 \pm 4 \%$ of the clusters were $<15 \mu \mathrm{m}$ (see Fig. $9 E, p B K)$. In contrast, in the cells expressing the dominant negative Src, $91 \pm 2 \%$ of the clusters were $<15 \mu \mathrm{m}$, whereas only $3 \pm 1 \%$ were $>25 \mu \mathrm{m}$ (Fig. $9 E, D N S r c$ ). These results provide strong evidence that Src-class kinases are critical for maturation of AChR clustering. 


\section{DISCUSSION}

It has been predicted that a protein tyrosine kinase downstream of MuSK directly phosphorylates the AChR (Burden, 1998; Sanes et al., 1998; Fuhrer et al., 1999; Sanes and Lichtman, 1999). In this study, MuSK was found to be complexed with the Src-class kinases Fyn and $\mathrm{Src}$ in the $\mathrm{C} 2$ mouse muscle cell line. These associations were enhanced by agrin and by increasing protein tyrosine phosphorylation. MuSK bound specifically to the $\mathrm{SH} 2$ domains of Fyn and Src, and this in vitro binding was dependent on autophosphorylation of MuSK. In addition, Fyn and Src phosphorylated MuSK in transfected cells. A highly selective inhibitor of Src-family kinases, PP1, blocked the enzymatic activity of Fyn and Src from C2 myotubes but did not affect the kinase activity of MuSK. With use of PP1, phosphorylation of MuSK and the AChR was demonstrated to be, in part, via Src-class kinases. In addition, Src-family kinases mediated agrin-induced anchoring of AChRs as well as maturation of AChR clustering. These data establish a structural and functional relationship for MuSK with Src and Fyn and provide evidence that Src-class kinases mediate the effects of agrin on the AChR.

\section{Role of AChR phosphorylation in clustering and anchoring}

The diffusion trap model proposes that after contact of the motor neuron with skeletal muscle, a "sticky zone" is created at the contact site where mobile AChRs become trapped (Edwards and Frisch, 1976). In support of this theory, nonsynaptic AChRs are able to migrate freely, whereas clustered receptors are less mobile in the membrane (Young and Poo, 1983; Podleski and Salpeter, 1988; Meier et al., 1995). Accumulation of AChRs at the nervemuscle contact site is due to migration of receptors to the developing endplate (Anderson and Cohen, 1977). Furthermore,
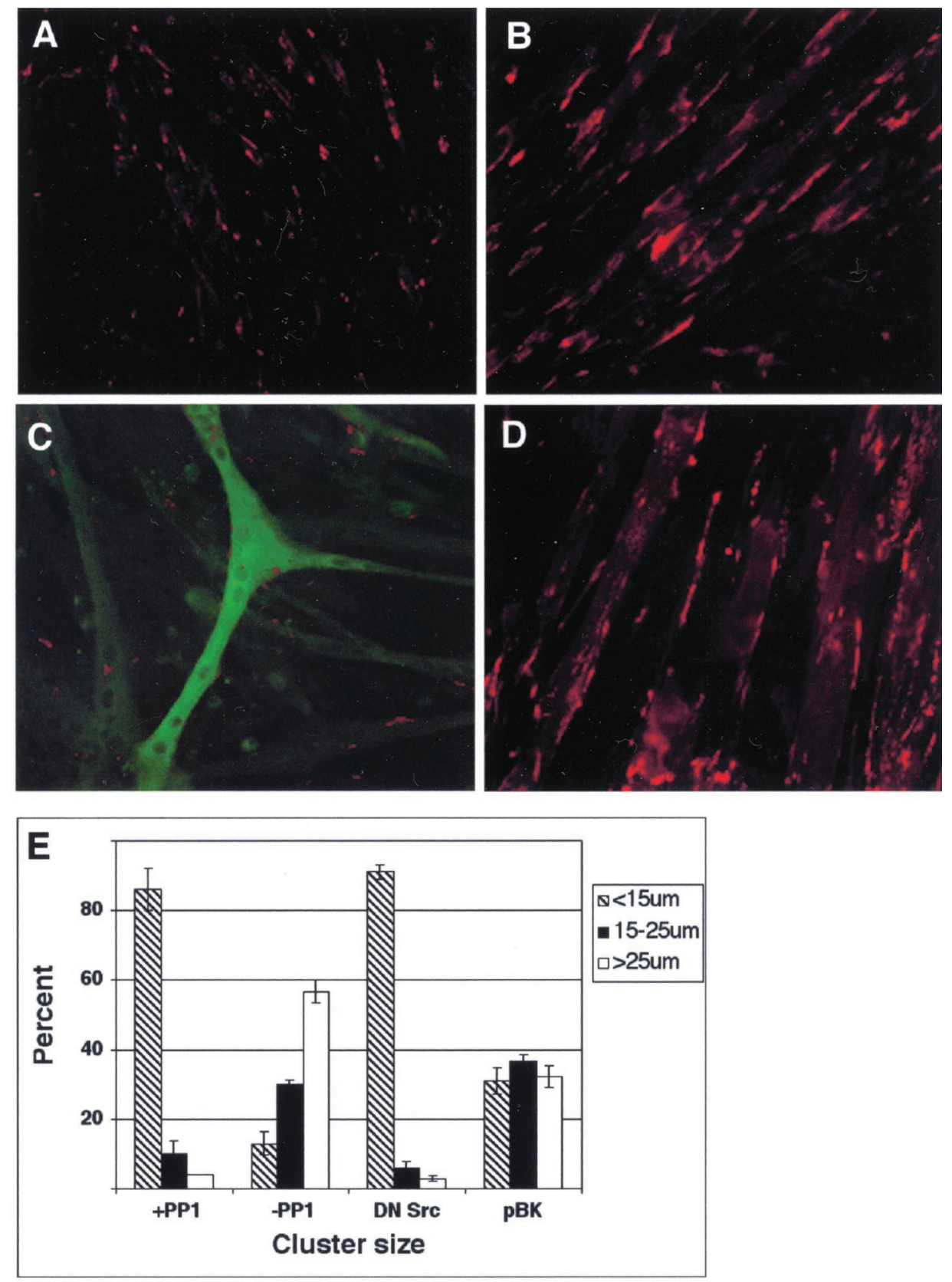

Figure 9. Effect of inhibiting Src-class kinases on agrin-induced $\mathrm{AChR}$ clustering. $A, B, \mathrm{C} 2$ myotubes were treated with $20 \mu \mathrm{M}$ PP1 $(A)$ or DMSO vehicle $(B)$ for $1 \mathrm{hr}$ followed by treatment with $100 \mathrm{pm}$ agrin for $12 \mathrm{hr}$ in the continued presence or absence of PP1. $C, D, \mathrm{C} 2$ myotubes were transfected with the dominant negative $\operatorname{Src}(C)$ or empty plasmid $(D)$. After 55-60 hr, cells were treated for $12 \mathrm{hr}$ with 100 pM agrin. For $A-D$, AChR clusters were visualized with Texas Red $\alpha$-bungarotoxin, whereas for $C$ and $D$, expression of the dominant negative Src was visualized by $\operatorname{src} 2$ staining, as described in Material and Methods. Scale bar, $20 \mu \mathrm{m}$. E, Cluster sizes were analyzed and binned into three categories: $<15,15-25$, and $>25 \mu \mathrm{m}$. The data represent the mean \pm SEM, $n=5$ experiments, for the effect of PP1 and $n=3$ experiments for the effect of dominant negative Src. For agrin - PP1, agrin + PP1, agrin on pBK-CMV-transfected cells, and agrin on dominant negative Src-transfected cells, a total of 523, 518, 673, and 417 clusters, respectively, were analyzed. Note: The change in the receptor size distribution between the control transfected cells and the DMSO control for the PP1 experiment derives from the fact that low concentrations of DMSO appeared to promote agrin-induced clustering. 
Figure 10. Hypothetical model for the role of Src-class protein tyrosine kinases in phosphorylation and cytoskeletal anchoring of AChRs at the NMJ AChRs are in a dynamic equilibrium between a dephosphorylated mobile state $(A)$ and a phosphorylated anchored state $(B)$. In the mobile state, AChRs are in a complex with MuSK, rapsyn, $\alpha$-dystroglycan $(\alpha D G)$, and Src-family kinases. As the mobile complex diffuses into the nascent endplate, where MuSK is activated by agrin, the autophosphorylation sites on MuSK bind the SH2 domains of Src-class kinases, resulting in their activation. Activated Src-class kinases subsequently phosphorylate the AChR $\beta$ and $\delta$ subunits. In addition, MuSK and rapsyn are also phosphorylated by Src-class kinases. AChR phosphorylation by Src-class ki-

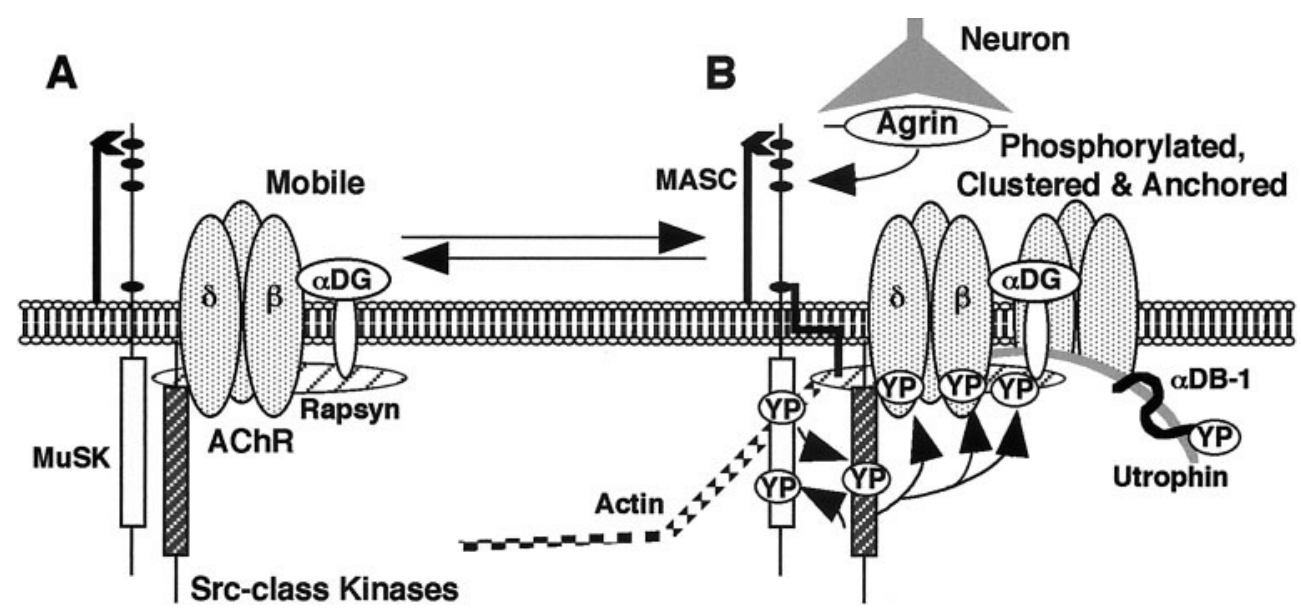
nases induces receptor anchoring to the actin cytoskeleton. Phosphorylation of rapsyn and/or $\alpha$-dystrobrevin- $1(\alpha D B-1)$ by Src-class or other kinases may also be important for formation and maturation of the NMJ endplate.

mathematical modeling demonstrates that free diffusion of AChRs is fast enough to account for receptor accumulation at the endplate during synapse formation (Edwards and Frisch, 1976; Chao et al., 1981; Young and Poo, 1983; Kuromi et al., 1985). Thus, trapping of receptors at the endplate is critical for synaptogenesis at the NMJ. The data presented here indicate that local activation of Src-class kinases may be a mechanism to create a sticky zone at the developing endplate.

Several lines of evidence support AChR tyrosine phosphorylation as a mechanism for receptor aggregation and stabilization within the cytoskeleton. Innervation induces AChR clustering and anchoring as well as receptor phosphorylation (Hall and Sanes, 1993; Qu and Huganir, 1994). Agrin also induces AChR phosphorylation and clustering (Godfrey et al., 1984; Wallace et al., 1991). Receptor phosphorylation in response to agrin precedes clustering, consistent with the idea that phosphorylation causes clustering (Wallace, 1992). Conditions that induce AChR phosphorylation, such as agrin treatment, cotransfection with Src-class kinases, and pervanadate treatment, also stimulate receptor anchoring (Wallace, 1992; Meier et al., 1995; Wallace, 1995; Mohamed and Swope, 1999). Furthermore, phosphorylation and anchoring of the AChR always occur with the same time course, suggesting a close functional relationship (Wallace, 1992, 1995). In addition, phosphorylated AChRs are more slowly extracted and hence are more tightly associated with the cytoskeleton than nonphosphorylated receptors (Meier et al., 1995). Conversely, protein tyrosine kinase inhibitors block AChR phosphorylation, clustering, and anchoring (Figs. 8, 9) (Wallace, 1994; Ferns et al., 1996; Mohamed and Swope, 1999). Of significance, a mutant AChR $\beta$ subunit lacking the tyrosine phosphorylation site assembles with endogenous AChR subunits of a muscle cell line, producing a receptor that forms only half the normal number of agrin-induced clusters. Furthermore, mutation of the $\beta$ subunit abolishes agrin-induced cytoskeletal anchoring of AChRs (Borges and Ferns, 2001). Thus, tyrosine phosphorylation of the AChR $\beta$ subunit can regulate anchoring and clustering of AChRs. The results reported here reinforce this conclusion and support Src-class kinases in mediating agrin-induced phosphorylation of AChRs.

Cytoskeletal anchoring of AChRs appears to be reversible, involving two dynamic processes: actin polymerization and binding of AChRs to the cytoskeleton. Formation of clusters is asso- ciated with local actin polymerization. Furthermore, the newly formed clusters are sites for continued actin assembly. In fact, the force generated by actin polymerization is sufficient to move AChR clusters within the membrane (Dai et al., 2000). AChR anchoring is also dynamic via reversible binding with the cytoskeleton. AChRs appears to exist in either a nonphosphorylated and mobile state or a phosphorylated and anchored state (Meier et al., 1995). Two pieces of evidence indicate that these two forms of the receptor must exist in a dynamic equilibrium. First, AChR phosphorylation and cytoskeletal anchoring in response to agrin occur before clustering (Wallace, 1992). Second, shifting the equilibrium far into the phosphorylated-anchored form of the AChR, using either pervanadate or viral Src, blocks receptor clustering, indicating that phosphorylated receptors are immobilized before they can aggregate (Anthony et al., 1984; Meier et al., 1995; Wallace, 1995). Therefore, cytoskeletal polymerization and attachment of AChRs to the cytoskeleton must be dynamically regulated for proper postsynaptic localization of receptors. The results presented here suggest that reversible phosphorylation of AChRs via Src-class kinases may provide a dynamic mechanism for regulating receptor anchoring.

\section{Role of additional phosphoproteins in synaptogenesis}

The endplate consists of a complex matrix of proteins (Sanes and Lichtman, 1999). Tyrosine phosphorylation is necessary for synaptogenesis at the NMJ; however, it is not known whether the AChR is the only important substrate. Several components of the postsynaptic complex, in addition to AChRs, are tyrosine phosphorylated. These proteins include rapsyn as well as $\alpha$-dystrobrevin-1 and syntrophin of the dystrophin glycoprotein complex (Wagner et al., 1993; Wagner and Huganir, 1994; Qu et al., 1996; Balasubramanian and Huganir, 1999; Mohamed and Swope, 1999). Phosphorylation of these proteins may also be important for promoting the cytoskeletal anchoring or proteinprotein interactions necessary for synaptogenesis. Both rapsyn and $\alpha$-dystrobrevin are crucial for normal synaptogenesis at the $\mathrm{NMJ}$; however, the structures of the NMJs in rapsyn and $\alpha$-dystrobrevin knock-out mice are different. In rapsyn ${ }^{-1-}$ myofibers, AChR clustering is completely absent in vivo as well as in response to agrin in culture (Gautam et al., 1995). Whether rapsyn phosphorylation regulates its critical role in synapse formation is an interesting question. In $\alpha$-dystrobrevin ${ }^{-/-}$mice, 
NMJs form but the AChRs have an abnormal, patchy distribution. In addition, agrin-induced formation of large AChR clusters is defective in myotubes derived from $\alpha$-dystrobrevin ${ }^{-1-}$ mice (Grady et al., 2000). Rapsyn and $\alpha$-dystrobrevin-1 appear to have very different molecular functions in forming the NMJ, and both are phosphorylated. Hence, in addition to anchoring of AChRs, protein tyrosine phosphorylation, perhaps via Src-family kinases, may regulate the critical role of rapsyn in synaptogenesis as well as the function of $\alpha$-dystrobrevin- 1 in endplate maturation.

\section{A molecular model for the role of Src-class kinases in synaptogenesis}

The results presented here provide a clearer picture of how agrin, MuSK, rapsyn, and Src-class kinases might regulate synapse formation at the NMJ. A current model for agrin-stimulated signal transduction and regulation of AChRs at the NMJ is depicted in Figure 10. In this model, the AChR exists in an equilibrium between a mobile nonphosphorylated state and an anchored phosphorylated state (Fig. $10 A, B$ ). Both the mobile and anchored AChRs may be in a complex of proteins including MuSK, Src-class kinases, rapsyn, and $\alpha$-dystroglycan of the dystrophin glycoprotein complex (Cohen et al., 1995; Fuhrer and Hall, 1996). The motoneuron, via released agrin, alters the equilibrium by stimulating local AChR phosphorylation and anchoring (Fig. 10A,B). Thus, the AChR/rapsyn/MuSK/Src-class kinases complex is recruited to nascent sites of endplate formation, which are thought to be marked by MuSK (Fuhrer and Hall, 1996; Apel et al., 1997). For this to occur, agrin activates MuSK via the postulated MuSK accessory specificity component (Glass et al., 1997). Stimulation of MuSK results in binding of Src or Fyn, or both, via their SH2 domains, to an autophosphorylation site(s) on MuSK (Figs. 1-3), which is a common mechanism for activation of Src-class kinases (Thomas and Brugge, 1997). Because these Src-family kinases have multiple roles in muscle cell function (Claycomb and Lanson, 1987; Castellani et al., 1995; Hirayama et al., 1997; Sanes and Lichtman, 1999), the pools of Src and Fyn activated by MuSK are small, as demonstrated recently (Mittaud et al., 2001). Activation of Src and Fyn by MuSK may be enhanced by rapsyn (Fig. 4) (Mohamed and Swope, 1999; Mittaud et al., 2001). Src and Fyn then phosphorylate MuSK (Figs. 4-7), rapsyn (Mohamed and Swope, 1999), and the AChR (Figs. 5, 7) (Swope and Huganir, 1993; Fuhrer and Hall, 1996; Mohamed and Swope, 1999). Thus, as the mobile receptors come near the nascent synapse, they are phosphorylated and trapped at the endplate via cytoskeletal anchoring, resulting in aggregation of receptors postsynaptically (Figs. 8, 9) (Mohamed and Swope, 1999). Furthermore, phosphorylation of additional postsynaptic elements, such as rapsyn and $\alpha$-dystrobrevin- 1 , may regulate the initiation of aggregation and/or stabilization and condensation of protein complexes. This model incorporates results from numerous studies and provides interesting hypotheses for future testing.

\section{REFERENCES}

Anderson MJ, Cohen MW (1977) Nerve-induced and spontaneous redistribution of acetylcholine receptors on cultured muscle cells. J Physiol (Lond) 268:757-773.

Anthony DT, Schuetze SM, Rubin LL (1984) Transformation by Rous sarcoma virus prevents acetylcholine receptor clustering on cultured chicken muscle fibers. Proc Natl Acad Sci USA 81:2265-2269.

Apel ED, Glass DJ, Moscoso LM, Yancopoulos GD, Sanes JR (1997) Rapsyn is required for MuSK signaling and recruits synaptic components to a MuSK-containing scaffold. Neuron 18:623-625.

Balasubramanian S, Huganir RL (1999) Characterization of phosphotyrosine containing proteins at the cholinergic synapse. FEBS Lett 446:95-102.

Barrantes FJ, Neugebauer DC, Zingshein HP (1980) Peptide extraction by alkaline treatment is accompanied by rearrangement of the membrane-bound acetylcholine receptor from Torpedo marmorata. FEBS Lett 112:72-78.

Biscardi JS, Maa MC, Tice DA, Cox ME, Leu TH, Parsons SJ (1999) c-Src-mediated phosphorylation of the epidermal growth factor receptor on Tyr845 and Tyr1101 is associated with modulation of receptor function. J Biol Chem 274:8335-8343.

Blount P, Merlie JP (1988) Native folding of an acetylcholine receptor $\alpha$-subunit expressed in the absence of other receptor subunits. J Biol Chem 263:1072-1080.

Borges LS, Ferns M (2001) Agrin-induced phosphorylation of the acetylcholine receptor regulates cytoskeletal anchoring and clustering. J Cell Biol 153:1-11.

Burden SJ (1998) The formation of neuromuscular synapses. Genes Dev $12: 133-148$

Burden SJ, DePalma RL, Gottesman GS (1983) Crosslinking of proteins in acetylcholine receptor-rich membranes: association between the $\beta$-subunit and the $43 \mathrm{kd}$ subsynaptic protein. Cell 35:687-692.

Castellani L, Reedy MC, Gauzzi MC, Provenzano C, Alema S, Falcone G (1995) Maintenance of the differentiated state in skeletal muscle: activation of v-Src sarcomeres in quail myotubes. J Cell Biol 130:871-885.

Chao NM, Young SH, Poo MM (1981) Localization of cell membrane components by surface diffusion into a "trap." Biophys J 36:139-153.

Chen D, Okayama H (1987) High efficiency transformation of mammalian cells by plasmid DNA. Mol Cell Biol 7:2745-2752.

Claesson-Welsh L (1994) Platelet-derived growth factor receptor signals. J Biol Chem 269:32023-32026.

Claycomb WC, Lanson Jr NA (1987) Proto-oncogene expression in proliferating and differentiating cardiac and skeletal muscle. Biochem J 247:701-706

Cohen I, Rimer M, Lomo T, McMahan UJ (1997) Agrin-induced postsynaptic-like apparatus in skeletal muscle fibers in vivo. Mol Cell Neurosci [Erratum (1997) 10:208] 9:237-253.

Cohen MW, Jacobson C, Godfrey EW, Campbell KP, Carbonetto S (1995) Distribution of alpha-dystroglycan during embryonic nervemuscle synaptogenesis. J Cell Biol 129:1093-1101.

Dai Z, Luo X, Xie H, Peng HB (2000) The actin-driven movement and formation of acetylcholine receptor clusters. J Cell Biol 150:1321-1334. DeChiara T, Bowen DC, Valenzuela DM, Simmons MV, Poueyirou WT, Thomas, S, Kinetz, E, Compton DL, Rojas, E, Park JS, Smith, C, DiStefano PS, Glass DJ, Burden SJ, Yancopoulos GD (1996) The receptor tyrosine kinase MuSK is required for neuromuscular junction formation in vivo. Cell 85:1-20.

DeLorbe WJ, Luciw PA, Goodman HM, Varmus HE, Bishop JM (1980) Molecular cloning and characterization of avian sarcoma virus circular DNA molecules. J Virol 36:50-61.

Edwards C, Frisch HL (1976) A model for the localization of acetylcholine receptors at the muscle endplate. J Neurobiol 7:377-381.

Feder D, Bishop JM (1990) Purification and enzymatic characterization of pp60c-src from human platelets. J Biol Chem [Erratum (1990) 265:14056] 265:8205-8211.

Ferns M, Deiner M, Hall Z (1996) Agrin-induced acetylcholine receptor clustering in mammalian muscle requires tyrosine phosphorylation. J Cell Biol 132:937-944.

Ferns MJ, Campanelli JT, Hoch W, Scheller RH, Hall ZW (1993) The ability of agrin to cluster AChRs depends on alternative splicing and on cell surface proteoglycans. Neuron 11:491-502.

Froehner SC, Luetje CW, Scotland PB, Patrick J (1990). The postsynaptic $43 \mathrm{~K}$ protein clusters muscle nicotinic acetylcholine receptors in Xenopus oocytes. Neuron 5:403-410.

Fuhrer C, Hall ZW (1996) Functional interaction of Src family kinases with the acetylcholine receptor in $\mathrm{C} 2$ myotubes. J Biol Chem 271:32474-32481.

Fuhrer C, Sugiyama JE, Taylor RG, Hall ZW (1997) Association of muscle-specific kinase MuSK with the acetylcholine receptor in mammalian muscle. EMBO J 16:4951-4960.

Fuhrer C, Gautam M, Sugiyama JE, Hall ZW (1999) Roles of rapsyn and agrin in interaction of postsynaptic proteins with acetylcholine receptors. J Neurosci 19:6405-6416.

Gautam M, Noakes PG, Mudd J, Nichol M, Chu GC, Sanes JR, Merlie JP (1995) Failure of postsynaptic specialization to develop at neuromuscular junctions of rapsyn-deficient mice. Nature 377:232-236.

Gautam M, Noakes PG, Moscoso L, Rupp F, Scheller RH, Merlie JP, Sanes JR (1996) Defective neuromuscular synaptogenesis in agrindeficient mutant mice. Cell 85:525-535.

Gillespie SK, Balasubramanian S, Fung ET, Huganir RL (1996) Rapsyn clusters and activates the synapse-specific receptor tyrosine kinase MuSK. Neuron 16:953-962.

Glass DJ, Bowen DC, Stitt TN, Radziejewski C, Bruno J, Ryan TE, Gies DR, Shah S, Mattson K, Burden SJ, DiStefano PS, Valenzuela DM, DeChiara TM, Yancopoulos GD (1996) Agrin acts via a MuSK receptor complex. Cell 85:513-523.

Glass DJ, Apel ED, Shah S, Bowen DD, DeChiara T, Stitt TN, Sanes JR, Yancopoulos GD (1997) Kinase domain of the muscle-specific receptor tyrosine kinase (MuSK) is sufficient for phosphorylation but not 
clustering of acetylcholine receptors: required role for the MuSk ectodomain? Proc Natl Acad Sci USA 94:8848-8853.

Gluzman Y (1981) SV40-transformed simian cells support the replication of early SV40 mutants. Cell 23:175-182.

Godfrey EW, Nitkin RM, Wallace BG, Rubin LL, McMahan UJ (1984) Components of Torpedo electric organ and muscle that cause aggregation of acetylcholine receptors on cultured muscle cells. J Cell Biol 99:615-627.

Grady RM, Zhou H, Cunningham JM, Henry MD, Campbell KP, Sanes JR (2000) Maturation and maintenance of the neuromuscular synapse: genetic evidence for roles of the dystrophin-glycoprotein complex. Neuron 25:279-293.

Hall ZW, Sanes JR (1993) Synaptic structure and development: the neuromuscular junction. Cell/Neuron C72/N10 [Suppl] 99-121.

Hanke JH, Gardner JP, Dow RL, Changelian PS, Brissette WH, Weringer EJ, Pollok BA, Connelly PA (1996) Discovery of a novel, potent, and Src family-selective tyrosine kinase inhibitor. J Biol Chem 271:695-701.

Hirayama E, Isobe A, Okamoto H, Nishioka M, Kim J (1997) Myogenin expression is necessary for commitment to differentiation and is closely related to Src tyrosine kinase activity in quail myoblasts transformed with Rous sarcoma virus. Eur J Cell Biol 72:133-141.

Huyer G, Liu S, Kelly J, Moffat J, Payette P, Kennedy B, Tsaprailis G, Gresser MJ, Ramachandran C (1997) Mechanism of inhibition of protein-tyrosine phosphatases by vanadate and pervanadate. J Biol Chem 272:843-851.

Iwasaki Y, Gay B, Wada K, Koizumi S (1998) Association of the Src family tyrosine kinase Fyn with TrkB. J Neurochem 71:106-111.

Jones G, Meier T, Lichtsteiner M, Witzemann V, Sakmann B, Brenner HR (1997) Induction by agrin of ectopic and functional postsynapticlike membrane in innervated muscle. Proc Natl Acad Sci USA 94:2654-2659.

Kuromi H, Brass B, Kidokoro Y (1985) Formation of acetylcholine receptor clusters at neuromuscular junction in Xenopus cultures. Dev Biol 109:165-176.

Liu Y, Bishop A, Witucki L, Kraybill B, Shimizu E, Tsien J, Ubersax J, Blethrow J, Morgan DO, Shokat KM (1999) Structural basis for selective inhibition of src family kinases by PP1. Chem Biol 6:671-678.

Lowry OH, Rosebrough NJ, Farr AL, Randall RJ (1951) Protein measurement with the folin phenol reagent. J Biol Chem 193:265.

Meier T, Perez GM, Wallace BG (1995) Immobilization of nicotinic acetylcholine receptors in mouse $\mathrm{C} 2$ myotubes by agrin-induced protein tyrosine phosphorylation. J Cell Biol 131:441-451.

Meier T, Hauser DM, Chiquet M, Landmann L, Ruegg MA, Brenner HR (1997) Neural agrin induces ectopic postsynaptic specializations in innervated muscle fibers. J Neurosci 17:6534-6544.

Mittaud P, Marangi PA, Erb-Vogtli S, Fuhrer C (2001) Agrin-induced activation of acetylcholine receptor-bound Src family kinases requires rapsyn and correlates with acetylcholine receptor clustering. J Biol Chem 276:14505-14513.

Mohamed A, Swope SL (1999) Phosphorylation and cytoskeletal anchoring of the acetylcholine receptor by Src-class protein tyrosine kinases: activation by rapsyn. J Biol Chem 274:20529-20539.

Moscovici C, Moscovici MG, Jimenez H, Lai MM, Hayman MJ, Vogt PK (1977) Continuous tissue culture cell lines derived from chemically induced tumors of Japanese quail. Proc Natl Acad Sci USA 11:95-103.

Oligino L, Lung FD, Sastry L, Bigelow J, Cao T, Curran M, Burke Jr TR, Wang S, Krag D, Roller PP, King CR (1997) Nonphosphorylated peptide ligands for the Grb2 Src homology 2 domain. J Biol Chem 272:29046-29052.

Phillips WD, Noakes PG, Roberds SL, Campbell KP, Merlie JP (1993) Clustering and immobilization of acetylcholine receptors by the 43-kD protein: a possible role for dystrophin-related protein. J Cell Biol 123:729-740.
Podleski TR, Salpeter MM (1988) Acetylcholine receptor clustering and triton solubility: neural effect. J Neurobiol 19:167-185.

Prives J, Fulton AB, Penman S, Daniels MP (1982) Interaction of the cytoskeletal framework with acetylcholine receptor on the surface of embryonic muscle cells in culture. J Cell Biol 92:231-236.

Qu Z, Huganir RL (1994) Comparison of innervation and agrin-induced phosphorylation of the nicotinic acetylcholine receptor. J Neurosci 14:6834-6841.

Qu Z, Apel ED, Doherty C, Hoffman PW, Merlie JP, Huganir RL (1996) The synapse-associated protein rapsyn regulates tyrosine phosphorylation of proteins colocalized at nicotinic acetylcholine receptor clusters. Mol Cell Neurosci 8:171-184.

Ratnam M, Sargent PB, Sarin V, Fox JL, Nguyen DL, Rivier J, Criado M, Lindstrom J (1986) Location of antigenic determinants on primary sequences of subunits of nicotinic acetylcholine receptor by peptide mapping. Biochemistry 25:2621-2632.

Rimer M, Mathiesen I, Lomo T, McMahan UJ (1997) gamma-AChR/ epsilon-AChR switch at agrin-induced postsynaptic-like apparatus in skeletal muscle. Mol Cell Neurosci 9:254-263.

Sanes JR, Lichtman JW (1999) Development of the vertebrate neuromuscular junction. Annu Rev Neurosci 22:389-442.

Sanes JR, Apel ED, Gautam M, Glass D, Grady RM, Martin PT, Nichol MC, Yancopoulos GD (1998) Agrin receptors at the skeletal neuromuscular junction. Ann NY Acad Sci 841:1-13.

Sugiyama J, Bowen DC, Hall ZW (1994) Dystroglycan binds nerve and muscle agrin. Neuron 13:103-115.

Swope SL, Huganir RL (1993) Molecular cloning of two abundant protein tyrosine kinases in Torpedo electric organ that associate with the acetylcholine receptor. J Biol Chem 268:25152-25161.

Swope SL, Huganir RL (1994) Binding of the nicotinic acetylcholine receptor to $\mathrm{SH} 2$ domains of fyn and fyk protein tyrosine kinases. J Biol Chem 269:29817-29824.

Swope SL, Moss SJ, Raymond LA, Huganir RL (1999) Regulation of ligand-gated ion channels by protein phosphorylation. Adv Second Messenger Phosphoprotein Res 33:49-78.

Thomas SM, Brugge JS (1997) Cellular functions regulated by Src family kinases. Annu Rev Cell Dev Biol 13:513-609.

Wagner KR, Huganir RL (1994) Tyrosine and serine phosphorylation of dystrophin and the 58-KDa protein in the postsynaptic membrane of Torpedo electric organ. J Neurochem 62:1947-1952.

Wagner KR, Cohen JB, Huganir RL (1993) The 87k postsynaptic membrane protein from Torpedo is a protein tyrosine kinase substrate homologous to dystrophin. Neuron 10:511-522.

Walker JH, Boustead CM, Witzemann V (1984) The 43-K protein, v1, associated with acetylcholine receptor containing membrane fragments is an actin-binding protein. EMBO J 3:2287-2290.

Wallace BG (1992) Mechnism of agrin-induced acetylcholine receptor aggregation. J Neurobiol 23:592-604.

Wallace BG (1994) Staurosporine inhibits agrin-induced acetylcholine receptor phosphorylation and aggregation. J Cell Biol 125:661-668.

Wallace BG (1995) Regulation of the interaction of nicotinic acetylcholine receptors with the cytoskeleton by agrin activated protein tyrosine kinase. J Cell Biol 128:1121-1129.

Wallace BG, Qu Z, Huganir RL (1991) Agrin induces phosphorylation of the nicotinic acetylcholine receptor. Neuron 6:869-878.

Yang W, Malek SN, Desiderio S (1995) An SH3-binding site conserved in Bruton's tyrosine kinase and related tyrosine kinases mediates specific protein interactions in vitro and in vivo. J Biol Chem 270:20832-20840.

Young SH, Poo MM (1983) Rapid lateral diffusion of extrajunctional acetylcholine receptors in the developing muscle membrane of Xenopus tadpole. J Neurosci 3:225-231. 